\title{
Photocatalytic Nanocomposite Materials Based on Inorganic Polymers (Geopolymers): A Review
}

\author{
Mahroo Falah ${ }^{1}\left(\mathbb{D}\right.$ and Kenneth J. D. MacKenzie ${ }^{2, *(1)}$ \\ 1 Fiber and Particle Engineering Research Unit, Faculty of Technology, University of Oulu, \\ 90014 Oulu, Finland; mahroo.falahpoorsichani@oulu.fi \\ 2 MacDiarmid Institute for MacDiarmid Institute for Advanced Materials and Nanotechnology, \\ School of Chemical and Physical Sciences, Victoria University of Wellington, Wellington 2820, New Zealand \\ * Correspondence: kenneth.mackenzie@vuw.ac.nz; Tel.: +64-45891948
}

Received: 13 September 2020; Accepted: 29 September 2020; Published: 9 October 2020

\begin{abstract}
Geopolymers are ecologically-friendly inorganic materials which can be produced at low temperatures from industrial wastes such as fly ash, blast furnace slags or mining residues. Although to date their principal applications have been seen as alternatives to Portland cement building materials, their properties make them suitable for a number of more advanced applications, including as photocatalytic nanocomposites for removal of hazardous pollutants from waste water or the atmosphere. For this purpose, they can be combined with photocatalytic moieties such as metal oxides with suitable bandgaps to couple with UV or visible radiation, or with carbon nanotubes or graphene. In these composites the geopolymers act as supports for the photoactive components, but geopolymers formed from wastes containing oxides such as $\mathrm{Fe}_{2} \mathrm{O}_{3}$ show intrinsic photoactive behaviour. This review discusses the structure and formation chemistry of geopolymers and the principles required for their utilisation as photocatalysts. The literature on existing photocatalytic geopolymers is reviewed, suggesting that these materials have a promising potential as inexpensive, efficient and ecologically-friendly candidates for the remediation of toxic environmental pollutants and would repay further development.
\end{abstract}

Keywords: geopolymers; photocatalysis; nanoparticles; degradation efficiency; $\mathrm{TiO}_{2} ; \mathrm{Cu}_{2} \mathrm{O}$; carbon nanotubes; graphene

\section{Introduction}

The development of materials to mitigate the effects of global warming and pollution generated by human activities is becoming a matter of increasing urgency. The ecological problems to which solutions are being sought are the increase in greenhouse gas emissions arising from the manufacture of ordinary Portland cement (OPC) and electricity generation by coal-fired power plants, especially in developing nations with increased demands for infrastructure. Ecologically-friendly alternatives to OPC which do not involve the high-temperature reaction of clay and limestone, generating large amounts of $\mathrm{CO}_{2}$, are inorganic polymers, otherwise known as geopolymers [1]. A further advantage of these materials over OPC is that they can be produced at temperatures from ambient to $80{ }^{\circ} \mathrm{C}$ by alkali activation of a range of aluminosilicate minerals [2-6], although geopolymers are now known to be less ecologically-friendly than previously claimed, given the production of the alkali activator and factors such as the energy-intensive processes by which some geopolymer precursors are produced [7]; these factors have often been overlooked or ignored by earlier proponents of geopolymers. Nevertheless, to date, the major interest in geopolymers has been as alternatives to OPC, although they have many other high-technology applications [8]. One such area of increasing interest is the mitigation of global environmental pollution problems, particularly air and water 
pollution. Over the past two or three decades, photocatalytic degradation of environmental pollutants by exploiting the conversion of solar to chemical energy has attracted considerable attention. Heterogeneous photocatalysts have many advantages over other photocatalysts, since they can be cost-effective, stable, non-toxic, strongly oxidising and effective at ambient temperature and pressure [9]. The combination of photocatalysts with geopolymers has been exploited in the construction industry to develop self-cleaning coatings for buildings, where the key factors are the aesthetic appearance and reasonable costs of cleaning maintenance [10]. Since geopolymers are environmentally friendly and can readily incorporate photocatalytically active materials such as $\mathrm{ZnO}, \mathrm{TiO}_{2}, \mathrm{CuO}$ and $\mathrm{Fe}_{2} \mathrm{O}_{3}$, they are an excellent option for construction applications. Geopolymers incorporated with photoactive materials in the presence of UV and UV-visible radiation [11] can oxidize and decompose the surface pollutants on a building or roadway, allowing the products to be subsequently easily removed later by rain, cleaning or washing with water because of the hydrophilic surface of such a photocatalytic geopolymer and the low contact angle for water, allowing it to slide off $[9,12,13]$.

A further ecological problem is associated with atmospheric pollution of waterways and the atmosphere resulting from manufacturing operations. A less well-researched but equally important environmental application of geopolymers has been as materials for the destruction of hazardous organic species in the atmosphere and in waterways. For this purpose, various photocatalytic species can be introduced into the geopolymer by exploiting its structure and chemistry, and the photocatalytic process can also be facilitated by the ability of the geopolymer to adsorb and immobilise the hazardous material in its structure. Thus, the combination of photocatalytic functionality with the environmental friendliness of geopolymers makes these potentially important materials for mitigation of climate change problems.

The present review outlines the important aspects of the synthesis and chemistry of aluminosilicate geopolymers, methods for the introduction of photocatalytic functionality by exploiting aspects of their structure and the applications of these photocatalysts for the remediation of ecological problems. The photocatalytic behaviour of geopolymer composites is typically investigated colorimetrically by monitoring the bleaching of a dye as a function of time. Since geopolymers can also act as adsorbents by virtue of their structure, the photocatalytic behaviour of geopolymer-based composites can only validly be determined by allowing the samples to come to equilibrium in the dark, before exposing them to UV or visible radiation. For a rigorous investigation, control experiments with the geopolymer alone should also be carried out, and attention should also be paid to the colour stability of the dye in the presence of the highly alkaline geopolymer. Unfortunately, some of the studies reported to date have not paid sufficient attention to these requirements, suggesting the necessity for a more rigorous approach in future studies. Although from a practical point of view, dye bleaching has been extensively used as a measure of photocatalytic behaviour, it would also be advisable in future studies not to rely solely on this as a measure of photocatalysis, but to augment this with an analysis of the reaction products.

\section{Aluminosilicate Geopolymers: Composition, Synthesis and Structure}

Although the term geopolymer has been applied to different types of material, including aluminosilicates activated with phosphoric acid, the most common class of geopolymers constitutes alkali-activated aluminosilicates, which, although having been known for many years, were first developed in their present form by Davidovits [1] by the action of alkali on dehydroxylated kaolin clay (metakaolin). These materials had the advantage of attaining strength at ambient or slightly elevated temperature and did not rely on the presence of crystalline phases for strength development. Davidovits also coined the name geopolymer by which these materials are now generally known. Alkali activation of other aluminosilicates such as coal fly ash [5] and ground blast furnace slag was soon found to produce aluminosilicate geopolymers with comparable or superior mechanical properties and these are now most commonly used as construction or engineering materials. However, although thermally pre-treated kaolin minerals are still the most commonly used aluminosilicate sources 
for specialised applications such as photocatalytic geopolymers, these minerals are commercially valuable, and the use of industrial wastes such as fly ash from coal-fired boilers for specialised geopolymer applications is attracting increasing attention.

Several synthetic methods for aluminosilicate geopolymers have been reported [8], but the most widely used is the reaction of a finely divided aluminosilicate source mineral or industrial waste material with an alkali metal hydroxide or a mixture of an alkali metal silicate and hydroxide. The setting characteristics of the resulting mixture can be controlled by adjusting the molar composition of the component oxides; in the case of metakaolin precursors, a molar ratio of $\mathrm{SiO}_{2} / \mathrm{Al}_{2} \mathrm{O}_{3}=3$, $\mathrm{M}_{2} \mathrm{O} / \mathrm{SiO}_{2}=0.3$ and $\mathrm{H}_{2} \mathrm{O} / \mathrm{M}_{2} \mathrm{O}=10$ was reported [2] to set well and give a product with good strength, but these ratios can vary quite widely. The resulting geopolymer mixture is cured and hardened at temperatures between ambient and $<100{ }^{\circ} \mathrm{C}$. The mechanism of geopolymer formation involves the formation of aluminate and silicate monomers by alkali attack on the solid aluminosilicate starting material; these units then condense to a metastable gel which then becomes more fully cross-linked, allowing it to set and harden [14]. Some of these reaction steps may be concurrent and overlap, and their kinetics can depend on the nature of the starting material and the activating solution. The steps of geopolymer synthesis are shown schematically in Figure 1.

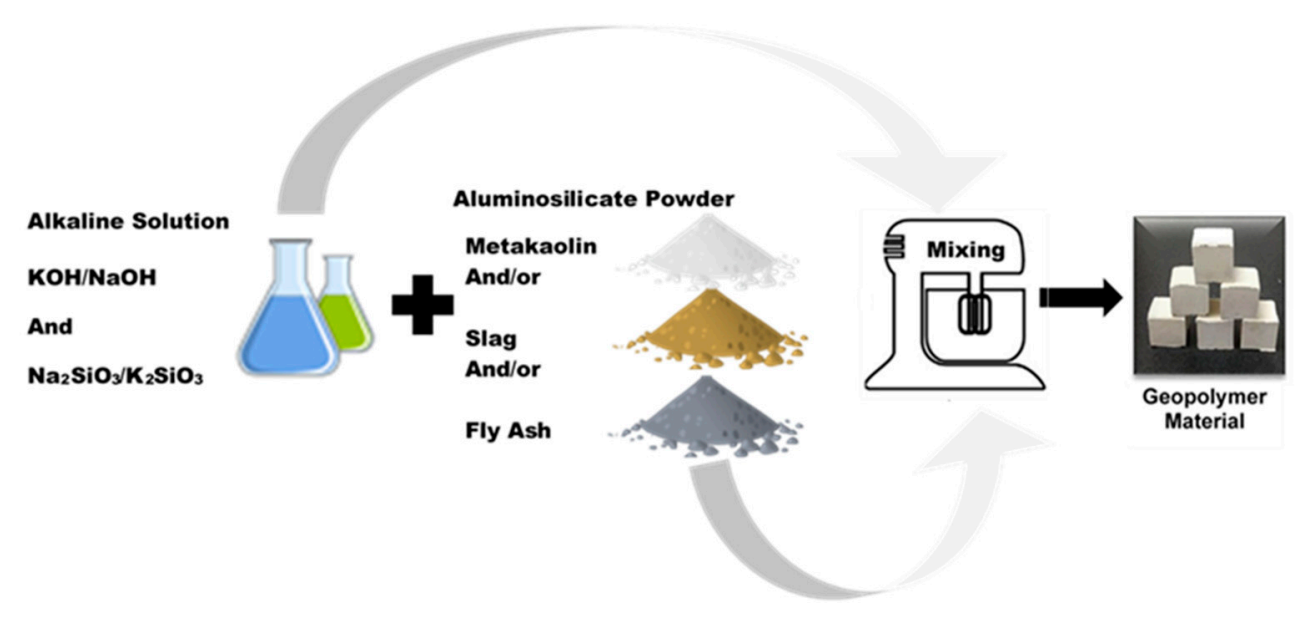

Figure 1. Schematic representation of the geopolymer synthesis procedure.

Aluminosilicate geopolymers each consist of a random three-dimensional array of tetrahedral aluminate and silicate units joined through their apical oxygens. Their lack of long-range crystallographic order is reflected in their characteristic broad X-ray diffraction pattern (similar to that of a glass) [2]. The fourfold-coordinated aluminium atoms in this structure have been shown by ${ }^{27} \mathrm{Al}$ solid-state MAS NMR spectroscopy to be formed during the alkaline reaction by conversion of $\mathrm{Al}(\mathrm{VI})$ and $\mathrm{Al}(\mathrm{V})$ of the precursor to $\mathrm{Al}(\mathrm{IV})[15,16]$, resulting in a negative charge on each $\mathrm{Al}$ which is balanced by a positively-charged ion, such as hydrated $\mathrm{Na}^{+}$or $\mathrm{K}^{+}$, located in the interstices of the gel structure [2] (Figure 2).

Since these charge-balancing ions are exchangeable, as in zeolites [17], they provide an important mechanism for manipulating the properties of the geopolymer, and in particular, they can be exploited to allow the introduction of photocatalytic moieties. 


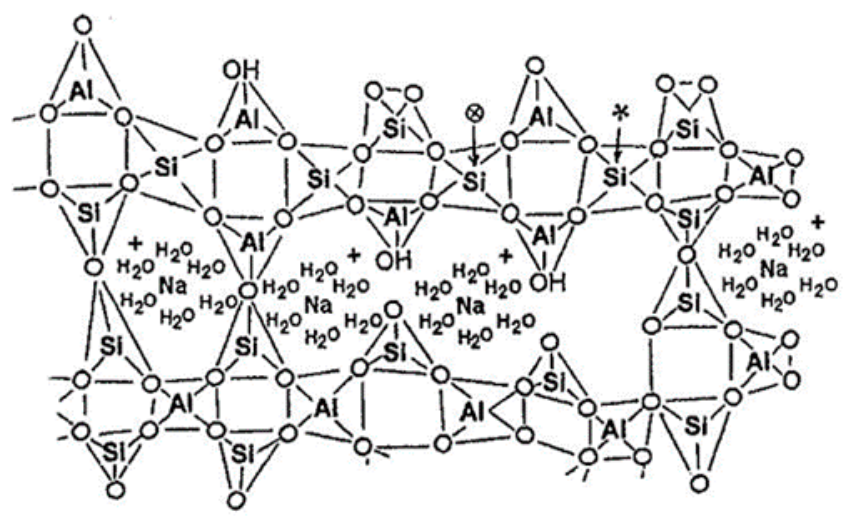

Figure 2. Semi-schematic structure for a Na-geopolymer.

\section{Mechanism of Photocatalysis in Geopolymers}

The photocatalysis mechanism in geopolymers is most usually extrinsic; i.e., it depends on the presence of an introduced semiconducting species such as $\mathrm{ZnO}$ or $\mathrm{CuO}$. The action of light quanta on the semiconductor promotes a photoelectron from the filled valence band to the vacant conduction band, provided the energy of the photon is greater than or equal to the bandgap of the semiconductor. In the presence of water, the resulting photogenerated pair of the hole in the valence band and the electron in the conduction band can then react to produce $\mathrm{HO}^{\bullet}$ radicals which are extremely powerful oxidising agents able to attack and destroy organic pollutants in solution. Concurrently, the holes in the valence band can react with oxygen to form anionic superoxide radicals, $\mathrm{O}_{2}^{-\bullet}$. These species are not only oxidising agents in their own right but are able to prevent electron-hole recombination and maintain electron neutrality in the photocatalyst. Protonation of the superoxide radical forms the hyperoxyl radical, $\mathrm{HO}_{2}{ }^{\bullet}$, two of which can either combine to form $\mathrm{H}_{2} \mathrm{O}_{2}+\mathrm{O}_{2}$, or two highly reactive hydroxyl radicals $\mathrm{OH}^{\bullet}+\mathrm{O}_{2}$. All these oxidising species are highly reactive, and can oxidize many organic compounds to $\mathrm{H}_{2} \mathrm{O}$ and $\mathrm{CO}_{2}$, or develop functional groups which increase their solubility, allowing them to be washed away. These processes are shown schematically in Figure 3.

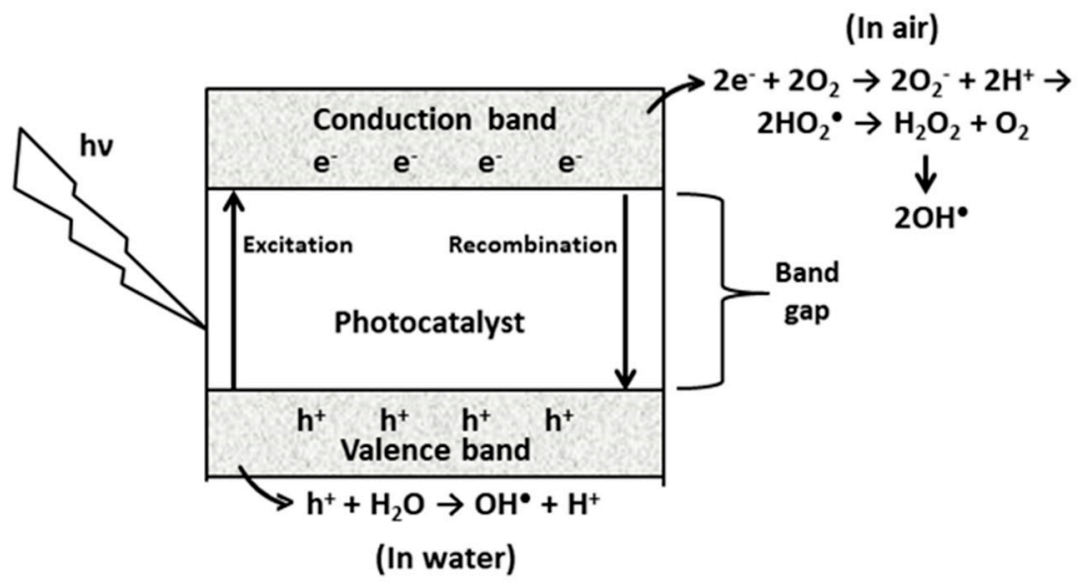

Figure 3. Schematic illustration of the photoactivation of a photocatalyst in water and air.

In greater detail, the photocatalytic process can be divided into four steps, namely:

(i) Photogeneration of hole/electron pairs by UV irradiation, promoting the photoelectron from the valence band of the semiconductor to the empty conduction band. This produces a positively-charged hole in the valence band $\left(\mathrm{h}^{+}(\mathrm{B})\right.$ and an electron in the conduction band $\mathrm{e}^{-}(\mathrm{CB})$ (Equation (1)).

$$
\text { Photocatalyst }+\mathrm{hv}(\mathrm{UV}) \rightarrow \mathrm{e}^{-}(\mathrm{CB})+\mathrm{h}^{+}(\mathrm{VB})
$$


(ii) Separation of hole/electron pairs and their diffusion to the surface of the electrode. In the presence of adsorbed water the positive holes in the valence band produce hydroxyl radicals (Equation (2)).

$$
\mathrm{H}_{2} \mathrm{O}(\text { ads })+\mathrm{h}^{+}(\mathrm{VB}) \rightarrow \mathrm{OH}^{\bullet}(\text { ads })+\mathrm{H}^{+}(\text {ads })
$$

These $\mathrm{OH}^{\bullet}$ radicals generated on the surface of the irradiated semiconductor are powerful oxidizing agents, able to attack adsorbed organic pollutants and destroy microorganisms.

(iii) Oxygen ion sorption. Reaction of atmospheric oxygen with the electron promoted to the conduction band generates the anionic superoxide radical $\left(\mathrm{O}_{2}^{-\bullet}\right)$ (Equation (3)).

$$
\begin{aligned}
& \mathrm{O}_{2}+\mathrm{e}^{-}(\mathrm{CB}) \rightarrow \mathrm{O}_{2}^{-\bullet}(\text { ads }) \\
& \mathrm{H}_{2} \mathrm{O}_{2} \text { (ads) } \rightarrow 2 \mathrm{OH}^{\bullet} \text { (ads) }
\end{aligned}
$$

In cases where an organic compound, such as one of the dyes commonly used as model compounds in photocatalytic experiments, has sufficient conjugation to absorb visible light, the photoactive semiconductor interacts with and destroys organic compound by exciting it with a photon of visible light $(\lambda>400 \mathrm{~nm})$ from the ground state to the triplet excited state. The triplet excited state injects an electron into the conduction band of the photocatalyst and is then converted into a semi-oxidized radial cation with the formation of superoxide radical anions $\left(\mathrm{O}_{2}^{-\bullet}\right)$ and hydroxyl radicals $\left(\mathrm{OH}^{\bullet}\right)$. These $\mathrm{OH}^{\bullet}$ radicals are mainly responsible for the oxidation of the organic compound, but the positive holes photogenerated in the valence band and the photogenerated electrons in the conduction band are also respectively responsible for oxidation and reduction of the organic compound [18-20]. It should be noted, however, that these reactions only apply to a limited number of organic materials, such as dyes which are able to absorb visible light.

The photocatalytic efficiency of a semiconductor depends both on the ability of the photocatalyst to produce holes and electrons and on the creation of reactive free radicals. Therefore, the specific surface area (SSA), morphology and bandgap of the photocatalyst are important properties which affect its efficiency. The bandgap is the distance between the valence band and the conduction band; and semiconductors, including $\mathrm{SnO}_{2}, \mathrm{MoO}_{3}, \mathrm{ZnO}, \mathrm{ZnS}, \mathrm{Fe}_{2} \mathrm{O}_{3}, \mathrm{WO}_{3}, \mathrm{CeO}_{2}, \mathrm{CdS}, \mathrm{ZrO}_{2}, \mathrm{SnO}_{2}, \mathrm{Cu}_{2} \mathrm{O}$ and $\mathrm{TiO}_{2}$, are commonly used as photocatalysts because of their unique electronic structures (occupied valence band and unoccupied conduction band) and sufficiently small bandgaps for solar excitation of an electron into the conduction band [21,22]. Ideally, a photocatalytic semiconductor for insertion into a geopolymer matrix should be capable of efficiently utilizing visible or near-UV radiation $(\lambda>400 \mathrm{~nm})$; it should also be biologically and chemically inert, photostable, inexpensive and non-toxic [23]. One oxide commonly used for this purpose is n-type $\mathrm{TiO}_{2}$, but its bandgap of $3.03 \mathrm{eV}$ is such that in normal sunlight only about $5 \%$ of the incident radiation is of suitable wavelength to photoexcite $\mathrm{TiO}_{2}$ [24]. Another photoactive semiconductor is p-type $\mathrm{Cu}_{2} \mathrm{O}$, with a bandgap of $2.172 \mathrm{eV}$ which couples well with visible radiation $(\lambda \leq 600 \mathrm{~nm})$ [25]. The bandgaps of these and other potential photoactive materials are listed in Table 1 , and photoactive geopolymers containing some of these materials are the subjects of this review.

Table 1. Band gap energies of various photocatalysts [26].

\begin{tabular}{cccc}
\hline Photocatalyst & Bandgap (eV) & Photocatalyst & Bandgap (eV) \\
\hline Diamond & 5.4 & $\mathrm{SnO}_{2}$ & 3.8 \\
Cubic $\mathrm{ZnS}$ & 3.6 & $\mathrm{SrTiO}_{3}$ & 3.4 \\
$\mathrm{ZnO}$ & 3.3 & $\mathrm{TiO}_{2}($ anatase $)$ & 3.2 \\
$\alpha-\mathrm{Fe}_{2} \mathrm{O}_{3}$ & 3.1 & $\mathrm{TiO}_{2}($ rutile $)$ & 3.0 \\
$\mathrm{WO}_{3}$ & 2.8 & $\mathrm{CdS}$ & 2.4 \\
$\mathrm{Fe}_{2} \mathrm{O}_{3}$ & 2.2 & $\mathrm{Cu}$ & 2.1 \\
$\mathrm{CdSe}$ & 1.7 & $\mathrm{CdTe}$ & 1.4 \\
$W{ }_{2}$ & 1.2 & $\mathrm{Si}$ & 1.1 \\
\hline
\end{tabular}




\section{Aluminosilicate Geopolymers with Photocatalytic Functionality}

\subsection{Geopolymer/TiO 2 Photocatalysts}

$\mathrm{TiO}_{2}$ is one of the more widely-used photocatalysts for environmental applications, such as water purification, air cleaning and self-cleaning surfaces, because of its good photocatalytic activity, chemical stability, low cost, long-term stability, ready availability and lack of toxicity [27-29]. One of the most challenging criteria for a suitable photocatalyst is that it must not rapidly recombine photogenerated electrons and holes. In the case of $\mathrm{TiO}_{2}$ its photocatalytic efficiency can be increased by incorporating it into a $\mathrm{TiO}_{2}$-based composite, thereby hindering its charge recombination [30]. In this way, $\mathrm{TiO}_{2}$ has been immobilized by incorporation into a number of different construction materials, including window glass, cement-based materials, bricks, ceramics and geopolymers, producing environmentally friendly self-cleaning and air purification products [31].

Strini et al. [32] demonstrated the use of $\mathrm{TiO}_{2}$-based photocatalytic geopolymers based on fly ash or metakaolin to decompose nitric oxide in air. The photocatalyst geopolymer was produced simply by mixing the geopolymer composition with P25 (a commercial mixture of rutile and anatase polymorphs of $\mathrm{TiO}_{2}$ ). The ideal amount of $\mathrm{TiO}_{2}$ was suggested to be $3 \mathrm{wt} . \%$ of the geopolymer paste, and the photocatalytic activity of the geopolymer composite depended on the type of binder and the curing conditions. The highest photocatalytic activity was found in $\mathrm{TiO}_{2} /$ fly ash-based geopolymer composite cured at room temperature, which resulted in twice the NO degradation rate compared with that of a $\mathrm{TiO}_{2} /$ metakaolin geopolymer [32]. The photocatalytic activity was also found to depend on the curing parameters; curing at $60^{\circ} \mathrm{C}$ produced a poorer photocatalyst, apparently due to segregation and depletion of the $\mathrm{TiO}_{2}$ in the catalyst surface [32].

Bravo et al. [33] synthesised metakaolin-based geopolymer spheres with photocatalytic activity by coating $\mathrm{TiO}_{2}$ nanoparticles on the surface of the spheres. These were produced by foaming an uncured geopolymer mixture with Polysorbate 80, and then dropping the mixture from a syringe into polyethylene glycol at $80^{\circ} \mathrm{C}$, which reduced the surface tension and resulted in the formation of beads $2-3 \mathrm{~mm}$ in diameter. After drying at room temperature for $24 \mathrm{~h}$ and then curing at $75^{\circ} \mathrm{C}$ for 2 days, the beads were then coated with $\mathrm{TiO}_{2}$ nanocrystals by heating them with $\mathrm{TiO}_{2}$ at $1200{ }^{\circ} \mathrm{C}$ inside a quartz tube under high vacuum. SEM images confirmed the complete dispersion of $\mathrm{TiO}_{2}$ within the geopolymer spheres. The photocatalytic activity of the $\mathrm{TiO}_{2} /$ geopolymer spheres in the degradation of methylene blue dye showed $90 \%$ degradation after $10 \mathrm{~h}$ of ultraviolet irradiation, compared with $4.5 \%$ degradation of the uncoated geopolymer spheres, but the brief experimental details of the photocatalytic experiments gave no indication as to how the processes of dye adsorption and photocatalysis were differentiated [33].

In another study, Chen et al. [31] deposited $\mathrm{TiO}_{2}$ films by a sol-gel dip-coating method on a geopolymer substrate based on $95 \%$ fly ash and 5\% metakaolin cured at room temperature. The geopolymer matrix was then dip-coated in a mixture of butyl titanate in ethanol with the addition of diethanolamine to increase the stability of the sol $[31,34]$. The dip-coated samples were then annealed at $500,600,700$ and $800^{\circ} \mathrm{C}$ for $1 \mathrm{~h}$ and showed desirable photocatalytic properties for the degradation of methylene blue dye [31], especially the sample annealed at $600{ }^{\circ} \mathrm{C}$ (Figure 4C), which was shown to contain the anatase phase of $\mathrm{TiO}_{2}$ and a mesoporous morphology (Figure 4A,B). Improved photocatalytic activity of the composites could be obtained by double layer sol-gel coating, resulting in an increased specific surface area, but conversely, it may also increase the probability of electron-hole pair recombination and decrease the photocatalytic performance. A further problem observed with the sol-gel coating technique was a tendency for the films to crack upon drying, but this could be offset by the addition of $6 \mathrm{wt}$.\% polyvinylpyrrolidine (PVP) [31]. Control experiments were also carried out under dark conditions to determine and correct for the degree of dye adsorption by the geopolymer alone. 

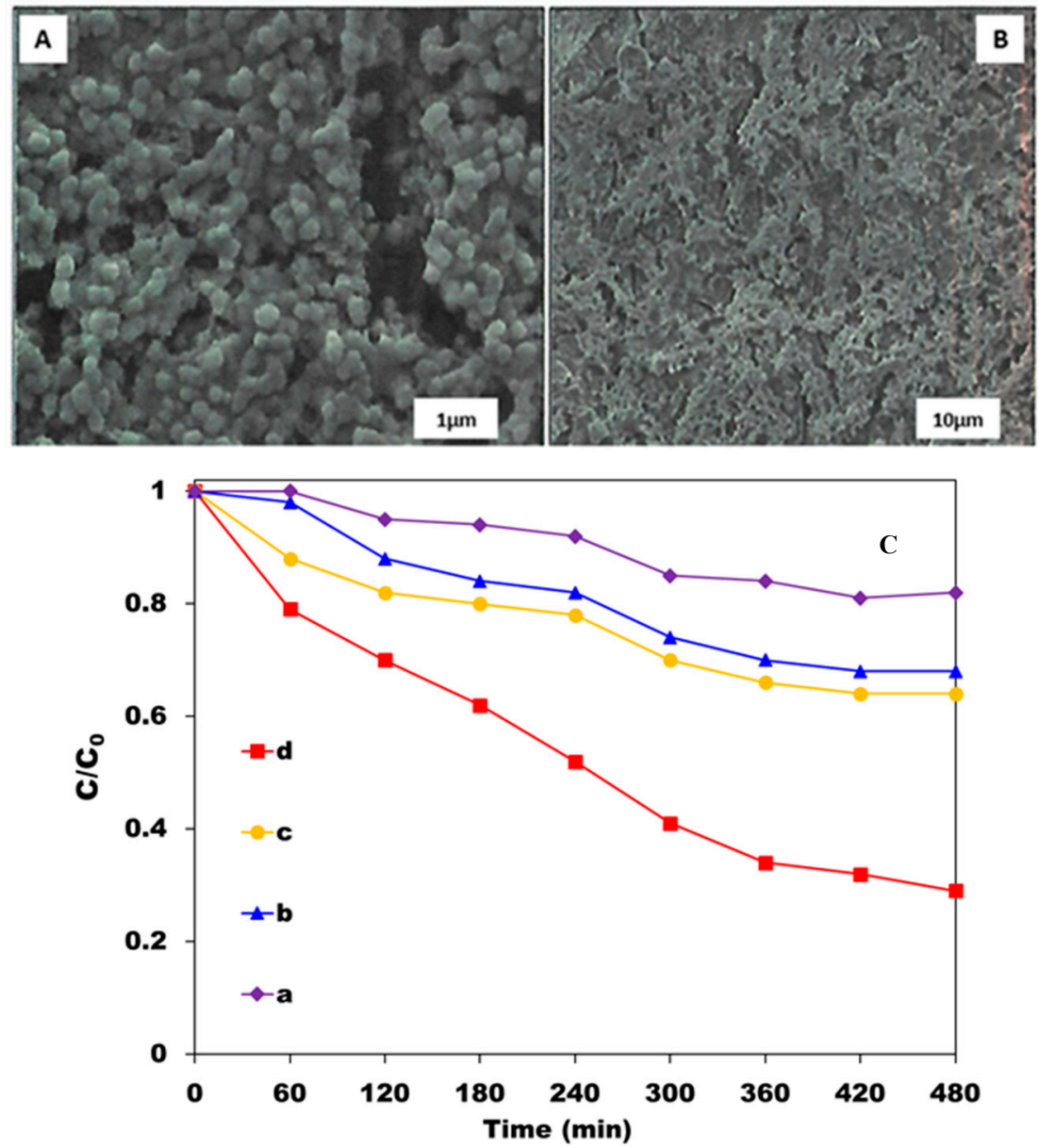

Figure 4. (A) SEM images of a dip-coated $\mathrm{TiO}_{2}$ film annealed at $600{ }^{\circ} \mathrm{C}$ for $1 \mathrm{~h}$. (B) Surface morphology of a typical multilayer-coated $\mathrm{TiO}_{2}$ film. (C) Residual dye concentration $\left(\mathrm{C} / \mathrm{C}_{0}\right)$ of methylene blue under $\mathrm{UV}$ irradiation by $\mathrm{TiO}_{2}$ films coated on a geopolymer, annealed at (a) $500{ }^{\circ} \mathrm{C}$, (b) $800{ }^{\circ} \mathrm{C}$, (c) $700{ }^{\circ} \mathrm{C}$, (d) $600{ }^{\circ} \mathrm{C}$, based on the data of Chen et al. [31].

Gasca- Tirado et al. [35] reported an alternative method for incorporating photoactive $\mathrm{TiO}_{2}$ into a metakaolin-based aluminosilicate inorganic polymer (geopolymer) by ion exchange with ammonium titanyl oxalate monohydrate, $\left(\mathrm{NH}_{4}\right)_{2} \mathrm{TiO}\left(\mathrm{C}_{2} \mathrm{O}_{4}\right)_{2} \cdot \mathrm{H}_{2} \mathrm{O}$. The efficiency of Ti incorporation was not improved by prior conversion of the geopolymer to the $\mathrm{NH}_{4}{ }^{+}$form. This ion exchange method was found to facilitate the growth of anatase-type $\mathrm{TiO}_{2}$ nanoparticles inside the geopolymer micropores, producing a photoactive geopolymer composite, demonstrated by its degradation of methylene blue (MB). Samples of the geopolymer composite, and for comparison, the geopolymer without $\mathrm{TiO}_{2}$, were equilibrated in the dark for a short time $(15 \mathrm{~min})$ prior to UV irradiation, and the results suggested only a small amount of dye adsorption had taken place after $80 \mathrm{~min}$, whereas almost all the methylene blue was bleached by the geopolymer photocatalyst, particularly the sample cured at $90{ }^{\circ} \mathrm{C}$ prior to ion exchange [35].

Yang et al. [36] studied the degradation of MB dye by foamed fly ash-based geopolymer- $\mathrm{TiO}_{2}$ nanocomposites produced in two different ways. The use of a foamed geopolymer matrix increased its porosity, allowing the incorporation of a higher concentration of $\mathrm{TiO}_{2}$ and improved contact with the dye solution. After alkali-activation, the fly ash geopolymer was foamed by the addition of oleic acid, followed by $\mathrm{H}_{2} \mathrm{O}_{2}$, and then cured at $80^{\circ} \mathrm{C}$. Two methods were investigated for incorporating $\mathrm{TiO}_{2}$ in the foamed geopolymer matrix; in one case the $\mathrm{TiO}_{2}$ (P25) was directly mixed into the foamed geopolymer prior to curing, whereas in a second procedure, the cured foamed matrix was treated with a solution of $\mathrm{TiO}_{2}$ in nitric acid, and then calcined at $500{ }^{\circ} \mathrm{C}$ to crystallize the $\mathrm{TiO}_{2}$ [36]. The most 
efficient photocatalytic degradation of $\mathrm{MB}$ dye was achieved in the composite containing $5 \mathrm{wt} . \% \mathrm{TiO}_{2}$ prepared by direct mixing, and was attained after $45 \mathrm{~min}$ of UV irradiation [36]. Prior to irradiation, the geopolymer photocatalyst samples for this experiment were equilibrated for $30 \mathrm{~min}$ in the dark to allow for adsorption effects, during which time the MB concentration was monitored, but the results show that equilibrium was not fully attained. Nevertheless, this study points to the potential of porous $\mathrm{TiO}_{2} /$ geopolymer composites derived from industrial by-products such as fly ash for the treatment of industrially discharged wastewater. Table 2 compares the different synthesis methods and photodegradation applications of $\mathrm{TiO}_{2}$ /geopolymer photocatalysts.

Table 2. Comparison of the different synthetic methods and $\mathrm{TiO}_{2} /$ geopolymer photocatalysts.

\begin{tabular}{|c|c|c|c|c|c|}
\hline Adsorbent & Preparation Method & $\mathrm{TiO}_{2}$ Type & $\mathrm{TiO}_{2}$ Content & Adsorbate & Reference \\
\hline $\begin{array}{l}\mathrm{TiO}_{2} / \mathrm{fly} \text { ash-metakaolin } \\
\text { geopolymer }\end{array}$ & Sol-Gel dip coating & Anatase, Rutile & NA & MB & Chen 2017 [31] \\
\hline $\begin{array}{c}\mathrm{TiO}_{2} / \text { metakaolin } \\
\text { geopolymer spheres }\end{array}$ & $\begin{array}{l}\text { Inside quartz tube at } \\
\text { high temperature }\end{array}$ & $\mathrm{P} 25$ & $10 \mathrm{mg}$ & MB & Bravo 2019 [33] \\
\hline
\end{tabular}

\subsection{Geopolymer/Graphene Photocatalysts}

Graphene Oxide (GO) is a derivative of graphene, a two-dimensional form of carbon that is attracting increasing interest as a functional material with useful properties such as high specific surface area, high electric conductance and good thermal conductivity. GO contains functional groups containing oxygen and can be synthesized by methods such as chemical oxidation and exfoliation of graphite [37] (Figure 5). The structure of GO is based on graphene and contains a number of oxygen functional groups (surface hydrophilic hydroxyl $(-\mathrm{OH})$ and epoxy $(\mathrm{C}-\mathrm{O}-\mathrm{C})$ groups and edge carboxyl $(-\mathrm{COOH})$ groups). These groups allow $\mathrm{GO}$ to be dispersed in water and provide many active sites for linking to other functional groups and organic molecules [38]. GO has attracted attention for adsorption and catalytic applications; in particular, its photonic properties suggest its potential for enhancing the photocatalytic properties of other materials. GO is typically suitable for the removal from water of organic dyes [39], antibiotics [40] and heavy metal ions [41].
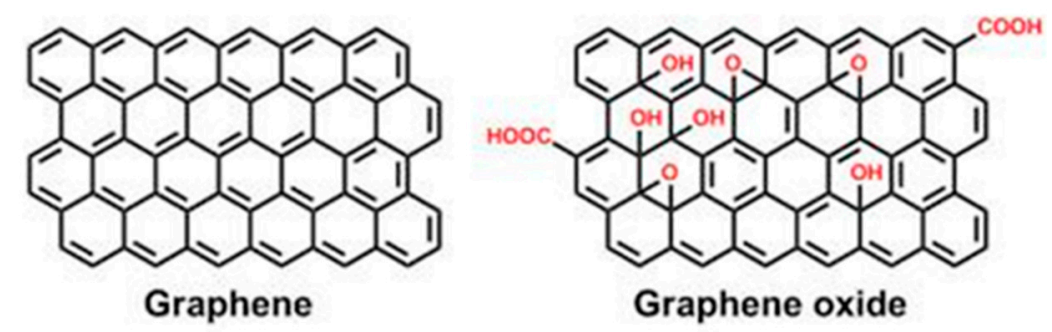

Figure 5. Structure of graphene and graphene oxide.

Lertcumfu et al. [37] studied the influences of GO additions on the photocatalytic properties of metakaolinite-based geopolymer composites and found that its addition can significantly improve the degradation of $\mathrm{MB}$ and $\mathrm{Cr}(\mathrm{VI})$ in comparison with pure geopolymer. The efficiencies of the $\mathrm{GO} /$ geopolymer composite for the removal of $\mathrm{MB}$ and $\mathrm{Cr}(\mathrm{VI})$ were $93 \%$ and $65 \%$ respectively. These authors reported that the adsorption process followed the pseudo second-order kinetic model with an $\mathrm{R}^{2}$ value $>98 \%$. Moreover, these GO/geopolymer composites showed a potential application for waste water treatment owing to their photocatalytic activity with a poor $C / C_{0}$ value of 0.6 after $2 \mathrm{~h}$ of UV irradiation. Zhang et al. [42] reported the photoactivity of a nanocomposite synthesized by the 
reaction of two- dimensional graphene with an alkali-activated granulated blast furnace slag (GBFS) geopolymer. This nanocomposite showed a high degree of methyl violet (MV) degradation under UV irradiation, especially in a composite containing $0.01 \mathrm{wt} . \%$ graphene, which had a degradation efficiency of $91.6 \%$ after $110 \mathrm{~min}$ of UV irradiation [42]. The degradation reaction of the MV dye followed a pseudo second-order kinetic model. Zhang et al. [43] reported the photocatalytic activity of a novel electroconductive graphene/fly ash-based geopolymer composite prepared by the incorporation of $1 \mathrm{wt} . \%$ of graphene into the alkali-activated geopolymer matrix prior to curing at room temperature. The addition of the graphene increased the electroconductivity of the composite by 348.8 times compared with that of the geopolymer without graphene, and the synergic effect of the graphene with the matrix red-shifted the maximum absorption wavelength of the composite into the visible region [43]. Furthermore, the presence of the graphene was shown by nitrogen adsorption-desorption isotherms to effectively improve the pore structure of the composite. The photoactive composite was found to degrade indigo carmine (IC) dye with an efficiency of $90.2 \%$, three times greater than the photocatalytic efficiency of the geopolymer matrix without graphene, and this catalytic performance for the removal of organic pollutants was unchanged after five cycling runs of UV irradiation [43]. Furthermore, the graphene structure was shown to be unchanged after the dye photodegradation cycles. The proposed mechanism involves interactions of the graphene with $\mathrm{Fe}_{2} \mathrm{O}_{3}$ particles from the fly ash geopolymer matrix in which the photogenerated electrons from the former are rapidly transferred to the $\pi$-conjugated system of the graphene, efficiently separating the photogenerated electron-hole pairs and allowing them to oxidize the $\mathrm{H}_{2} \mathrm{O}$ molecules adsorbed on the iron oxide surfaces. The resulting hydroxyl radicals oxidize and degrade the dye molecules adsorbed on the iron oxide surfaces [43]. In experiments to further confirm this mechanism, it was found that the addition of benzoquinone, which traps hydroxyl radicals, reduced the dye degradation efficiency from $91.6 \%$ to $70.8 \%$, whereas the addition of tertiary butyl alcohol, which traps superoxide radicals, reduced the degradation efficiency to $35.1 \%$ (Figure 6). These experiments suggest that graphene can act as an electron acceptor to enhance the oxidation degradation capacities of geopolymers.

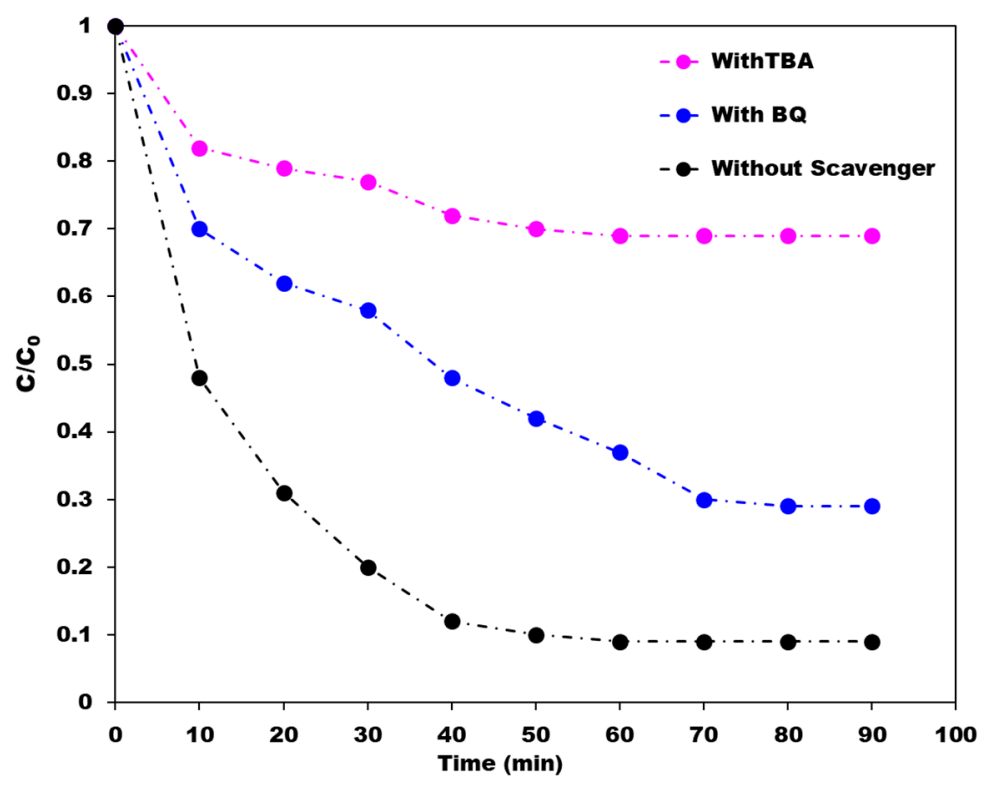

Figure 6. The effects of tertiary butyl alcohol (TBA) and benzoquinone (BQ) radical scavengers on the residual dye concentration $\left(C / C_{0}\right)$ of indigo carmine dye, based on the data of Zhang et al. [43].

Table 3, which summarises the reported investigations of photoactive geopolymers containing graphene or graphene oxide, highlights the varying experimental conditions used by different researchers, making a direct comparison of the photocatalytic results impossible. Although the available 
research data on these graphene/geopolymer photocomposites are very promising, considerably more theoretical and experimental research is required on these systems.

Table 3. Summary of the different studies on graphene and graphene oxide geopolymer photocatalysts.

\begin{tabular}{ccccc}
\hline Matrix & $\begin{array}{c}\text { Preparation } \\
\text { Method }\end{array}$ & $\begin{array}{c}\text { Graphene } \\
\text { Content (\%) }\end{array}$ & Adsorbate & Reference \\
\hline $\begin{array}{c}\text { graphene/fly ash-based } \\
\text { geopolymer }\end{array}$ & Mixing & $0.1,0.4,0.7$ and 1 & Indigo carmine & Zhang 2018 [43] \\
\hline $\begin{array}{c}\text { graphene oxide/calcined } \\
\text { kaolinite-based geopolymer }\end{array}$ & Mixing & $0,2.5,5$, and 10 & Methylene blue & Lertcumfu 2020 [37] \\
\hline $\begin{array}{c}\text { graphene/blast furnace } \\
\text { slag-based geopolymer }\end{array}$ & Mixing & 0.01 & Methyl violet & Zhang 2016 [42] \\
\hline
\end{tabular}

\subsection{Geopolymer/Cu $\mathrm{C}_{2} \mathrm{O}$ Photocatalysts}

$\mathrm{Cu}_{2} \mathrm{O}$, a prominent p-type semiconductor, acts as a photocatalyst under visible light irradiation $(\leq 600 \mathrm{~nm})$. Its direct bandgap energy of $2.2 \mathrm{eV}$ is readily excited by wavelengths in the visible region, giving it a significant absorption coefficient (up to $\approx 10^{4} \mathrm{~cm}^{-1}$ ) in this region. This suggests that $\mathrm{Cu}_{2} \mathrm{O}$ should act as a stable photocatalyst for the photochemical decomposition of $\mathrm{H}_{2} \mathrm{O}$ with the generation of $\mathrm{O}_{2}$ and $\mathrm{H}_{2}$ under visible light irradiation, and that it should also be a suitable candidate for the photocatalytic degradation of organic pollutants under visible light irradiation. The photocatalytic possibilities of $\mathrm{Cu}_{2} \mathrm{O}$ were investigated by Huang et al. [44] who demonstrated its photodegradation of methyl orange, but reported that it was readily deactivated by photocorrosion, especially when in the form of nanoparticles [44]. An improvement in its catalytic performance was obtained with larger microparticles which underwent photocorrosion more slowly, and its performance was also improved by the addition of $0.1 \mathrm{mmol} / \mathrm{L}$ of methanol which acted as a hole scavenger [44]. The photocatalytic behaviour of the different well-formed crystal facets of $\mathrm{Cu}_{2} \mathrm{O}$ microcrystals with well-formed facets was investigated by Zheng et al. [45]. They observed that during the photodegradation of methyl orange, the $\{100\}$ and $\{110\}$ faces gradually transformed into the $\{111\}$ facets of nanosheets which exhibit stable photocatalytic activity. These results, and the low toxicity, low cost and environmental friendliness of $\mathrm{Cu}_{2} \mathrm{O}$ suggest its use as a possible alternative to other common photocatalysts such as $\mathrm{TiO}_{2}$ for the photocatalytic degradation of organic contaminants, particularly when combined with ecologically-friendly geopolymers. These considerations led Fallah et al. [25] to investigate a novel photoactive inorganic polymer composite containing copper(I) oxide nanoparticles. The $\mathrm{Cu}_{2} \mathrm{O}$ nanoparticles were synthesized by the solution precipitation method, producing cubic crystallites of nanometre size. Metakaolin-based $\mathrm{Cu}_{2} \mathrm{O} /$ geopolymer composites were prepared by mixing $10-30 \mathrm{wt} . \%$ of pre-synthesized $\mathrm{Cu}_{2} \mathrm{O}$ nanoparticles with the geopolymer paste and curing for $12 \mathrm{~h}$ under ambient temperature. The photocatalytic activity of the $\mathrm{Cu}_{2} \mathrm{O} /$ geopolymer composite in the degradation of methylene blue (MB) was studied under the UV irradiation [25]. In a preliminary experiment, the adsorption of $\mathrm{MB}$ dye by geopolymer composites of varying $\mathrm{Cu}_{2} \mathrm{O}$ content was determined in the dark (Figure $7 \mathrm{~A}$ ), indicating that at $20 \% \mathrm{Cu}_{2} \mathrm{O}$ content, adsorption approached equilibrium at $30 \mathrm{~min}$. With higher $\mathrm{Cu}_{2} \mathrm{O}$ content, ingress of the dye solution into the pores of the substrate became progressively impeded, although the nano- $\mathrm{Cu}_{2} \mathrm{O}$ itself did not adsorb the methylene blue dye. Under UV radiation, the composites removed the $\mathrm{MB}$ dye from solution with a combination of adsorption and photodegradation (Figure 7B). In the dark, photocatalysis cannot occur and the process is by adsorption alone, evidenced by essentially similar behaviour of the geopolymer matrix under dark and UV conditions. By contrast, the geopolymer containing $\mathrm{Cu}_{2} \mathrm{O}$ showed improved removal of the dye under UV irradiation without deterioration of the geopolymer structure or the photoactive $\mathrm{Cu}_{2} \mathrm{O}$ component, as shown by ${ }^{63} \mathrm{Cu}$ NQR spectroscopy [25]. This study suggested that these geopolymer composites should function as useful new materials for the removal of organic pollutants from water or the atmosphere. The degradation of the MB dye followed a pseudo-second order kinetic model [25]. 

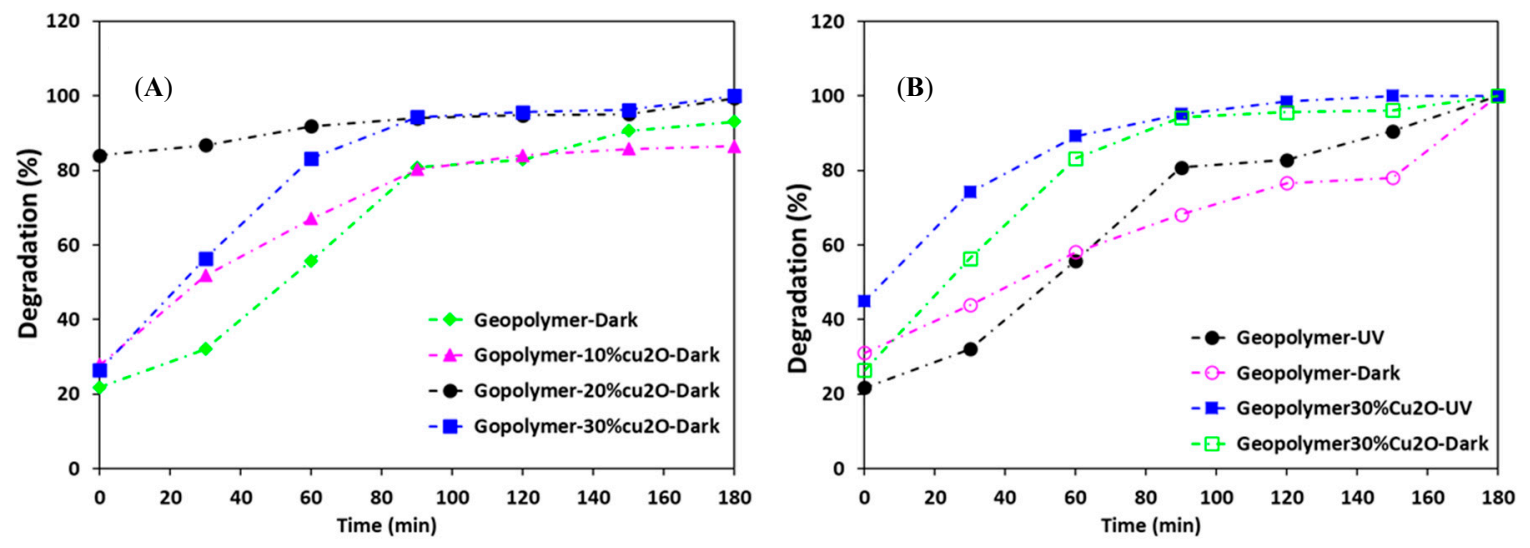

Figure 7. (A) Removal of methylene blue dye upon exposure to the geopolymer matrix (GP) and the $\mathrm{Cu}_{2} \mathrm{O}$-geopolymer composites of various compositions versus time in the dark; (B) comparison of the removal of methylene blue dye by the geopolymer matrix and the $30 \mathrm{wt}$. $\% \mathrm{Cu}_{2} \mathrm{O}$-geopolymer composite in the dark and under UV illumination. Based on the data of Falah et al [25].

\subsection{Geopolymer/Carbon Nanotube Photocatalysts}

Carbon nanotubes (CNTs) are graphite sheets rolled up into cylinders with partly one-dimensional nanostructures. CNTs have diameters of a few nanometres and lengths of some millimetres. CNTs can occur as single-walled nanotubes (SWCNTs), double-walled nanotubes (DWCNTs) and multi-walled nanotubes (MWCNTs), the latter consisting of multiple layers of graphite arranged in concentric cylinders [46]. CNTs have been successfully used as catalyst-supporting materials with properties superior to those of other regular catalyst supports. CNTs have large specific surface areas and have excellent capacities for absorbing toxic materials such as nitrogen oxides and polluted waste water $[47,48]$. They are also useful for reinforcing geopolymers. Bi et al. [49] synthesised metakaolin-based geopolymer nanocomposites containing CNTs by ultrasonically dispersing $0.1,0.25$, and 0.5 vol.\% of CNTs into a mixture of $\mathrm{NaOH}$ and sodium silicate solution, followed by blending with metakaolin powder, curing at $40{ }^{\circ} \mathrm{C}$ for $2 \mathrm{~h}$ and aging at $60^{\circ} \mathrm{C}$ for $24 \mathrm{~h}$. Before use, the CNTs were given a surface silica coating by treatment with a mixture of $\mathrm{H}_{2} \mathrm{SO}_{4}$ and $\mathrm{HNO}_{3}$, followed by a mixture of TEOS and $\mathrm{NH}_{4} \mathrm{OH}$. The resulting good distribution of the CNTs in the geopolymer matrix and the interfacial interaction between the $\mathrm{SiO}_{2}$ coating and the geopolymer matrix (Figure 8) were found significantly to improve the mechanical properties of the geopolymer nanocomposites [49] and suggested their application as a self-sensing structural material with ultrahigh sensitivity. Although the possible use of these composites as photoactive materials has not yet been investigated, the photoactive properties of the closely-related graphene/geopolymer composites (Section 4.2) suggest an investigation of the CNT/geopolymer composites would be worthwhile.

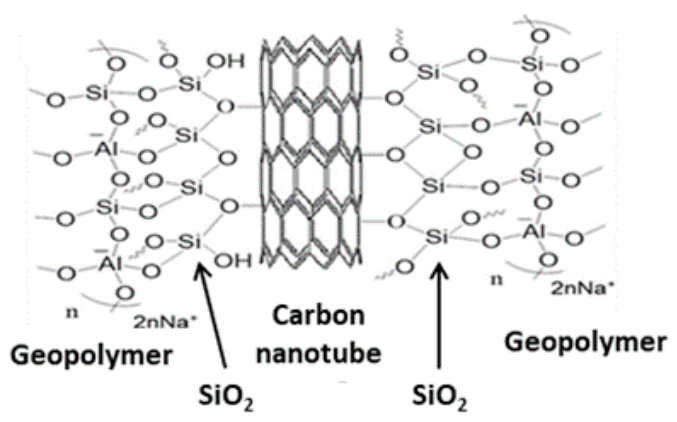

Figure 8. Schematic representation of the interface between a $\mathrm{SiO}_{2}$-treated carbon nanotube surface and a geopolymer matrix. 


\subsection{Other Geopolymer Photocatalysts}

Following their previous promising results using $\mathrm{Cu}_{2} \mathrm{O}$ for the photocatalytic degradation of methyl orange [44], Huang et al. [50] obtained an improved photocatalyst by combining $\mathrm{TiO}_{2}$ with $\mathrm{Cu}_{2} \mathrm{O}$. Their $\mathrm{Cu}_{2} \mathrm{O}-\mathrm{TiO}_{2}$ heterostructures, prepared by an alcohol-aqueous-based chemical precipitation method, showed greatly improved photocatalytic activity compared with pure $\mathrm{TiO}_{2}$ (P25), especially 50:50 $\mathrm{Cu}_{2} \mathrm{O}-\mathrm{TiO}_{2}$ compositions [50]. The photocatalytic efficiencies of these for the degradation of acid orange II dye were reported to be six times greater than pure $\mathrm{TiO}_{2}$ under UV-visible light, and 27 times greater under visible light [50]. Based on these findings, Falah et al. [51] prepared novel photoactive composites of spherical $\mathrm{Cu}_{2} \mathrm{O}-\mathrm{TiO}_{2}$ nanoparticles with aluminosilicate geopolymers which would act as both adsorbents and photocatalysts. The synthesis procedure of the $\mathrm{Cu}_{2} \mathrm{O}-\mathrm{TiO}_{2}$ nanoparticles from copper acetate and $\mathrm{TiO}_{2}$ (P25) is shown schematically in Figure 9. After SEM characterization of the heterostructured nanoparticles, 10-30 wt. $\%$ of them were added to an uncured metakaolin-based geopolymer mixture and cured at room temperature [51]. In the absence of photodegradation, under dark conditions, neither $\mathrm{TiO}_{2}$ nor $\mathrm{Cu}_{2} \mathrm{O}$ were found to adsorb methylene blue dye, but the geopolymer photocatalyst adsorbed the dye, following first-order kinetics and Freundlich-type isotherms. The adsorption process was less efficient in geopolymer composites containing $10 \mathrm{wt} . \%$ of $\mathrm{Cu}_{2} \mathrm{O}-\mathrm{TiO}_{2}$ than in the geopolymer matrix alone, probably due to blocking of the adsorption sites by the oxide nanoparticles. Under $\mathrm{UV}$ irradiation, the $\mathrm{Cu}_{2} \mathrm{O}-\mathrm{TiO}_{2}$ geopolymer composite removed the methylene blue dye through a combination of adsorption and photodegradation without destroying the geopolymer structure [51], suggesting that these new geopolymer composites should be suitable for efficiently removing organic pollutants from water or the atmosphere.

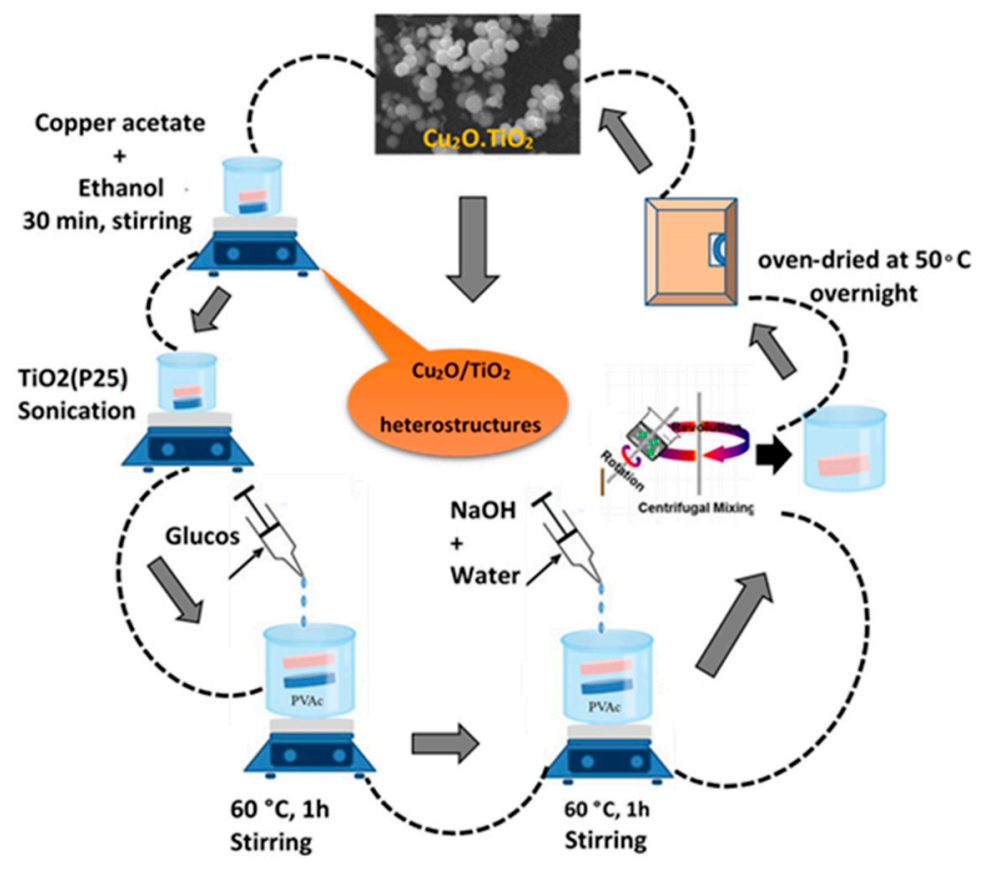

Figure 9. Schematic diagram of the synthesis of $\mathrm{Cu}_{2} \mathrm{O}-\mathrm{TiO}_{2}$ nanoparticles by an alcohol-aqueous-based chemical precipitation method.

The previous study by Falah et al. [51] of $\mathrm{Cu}_{2} \mathrm{O}-\mathrm{TiO}_{2}$ geopolymer photocatalysts indicated that these materials can play a dual adsorption-photoactive role, but the presence of the nanoparticle oxides can hinder adsorption by blocking the pores in the geopolymer matrix. This consideration led Falah et al. [52] to modify the geopolymer matrix by exchanging the charge-balancing $\mathrm{Na}^{+}$ions for the large tertiary ammonium ion cetyltrimethylammonium bromide, (CTAB) with the aim of facilitating access of the $\mathrm{Cu}_{2} \mathrm{O}-\mathrm{TiO}_{2}$ nanoparticles to the expanded geopolymer pores. The amount 
of $\mathrm{CTAB}$, based on the cation exchange capacity of the starting clay, was added, together with $\mathrm{Cu}_{2} \mathrm{O}-\mathrm{TiO}_{2}$ nanospheres prepared as in [51], to a metakaolin-based geopolymer composition prior to curing at $40{ }^{\circ} \mathrm{C}$. BET and TEM measurements of the CTAB-modified geopolymer composites showed that the insertion of the large ion resulted in an increase in the amount of the oxide catalyst entering the pore structure of the geopolymer. This was consistent with measurements of the removal of methylene blue from solution under UV irradiation after equilibration in the dark (Figure 10). The CTAB-modified geopolymer matrix alone showed a $9.4 \%$ increase in the removal of the MB dye compared with the unmodified matrix, compared with a $42.3 \%$ increase for the CTAB-modified $\mathrm{Cu}_{2} \mathrm{O}-\mathrm{TiO}_{2}$-geopolymer (Figure 10). By contrast, much smaller differences were found between the unmodified and CTAB-modified compounds containing only $\mathrm{Cu}_{2} \mathrm{O}$ or $\mathrm{TiO}_{2}$. A further experimental advantage of the photoactive geopolymers based on a CTAB-modified matrix is their improved ability to distinguish between adsorption and photodegradation processes; CTAB modification of the pore surfaces prevents the continuous change of $\mathrm{pH}$ throughout the adsorption process, allowing the two dye removal mechanisms to be separated [51]. These results suggest that further experiments to modify the geopolymer matrix may prove fruitful.

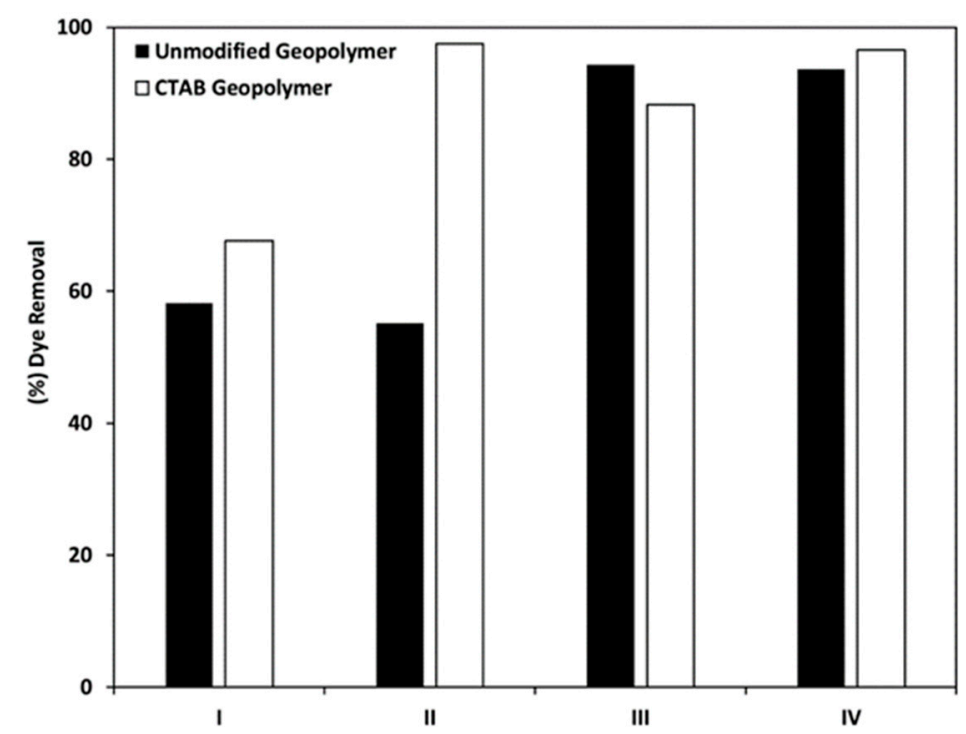

Figure 10. Removal of methylene blue dye from solution after equilibration in the dark, followed by 90 min of UV irradiation of composites based on CTAB-modified geopolymer matrices compared with geopolymers based on unmodified matrices. (I) geopolymer matrix alone, (II) $10 \mathrm{wt} \%$ $\mathrm{Cu}_{2} \mathrm{O}-\mathrm{TiO}_{2}$-geopolmer, (III) 10 wt. $\% \mathrm{Cu}_{2} \mathrm{O}$ /geopolymer, (IV) 10 wt. $\% \mathrm{TiO}_{2} /$ geopolymer. Based on data from Falah et al. [51,52].

Zailan et al. [53] studied the effect of $\mathrm{ZnO}$ nanoparticles on the photocatalytic degradation of methylene blue by F-class fly ash- based geopolymers under ultraviolet irradiation. $\mathrm{ZnO}$ nanoparticles (2.5-10 wt.\%) were dry-mixed with the fly ash prior to activation with sodium silicate and sodium hydroxide. The $\mathrm{ZnO} / \mathrm{fly}$ ash geopolymer composite showed satisfactorily efficient photocatalytic degradation of methylene blue after $150 \mathrm{~min}$ of exposure to sunlight, and by increasing the $\mathrm{ZnO}$ content, more active sites were produced on the photocatalyst's surface, increasing the numbers of hydroxyl and superoxide radicals, thereby facilitating the photodegradation of the dye. The effect of $\mathrm{ZnO}$-based geopolymer paste surfaces containing various amounts of $\mathrm{ZnO}$ on the photocatalytic degradation of methylene blue dye under UV light is shown in Figure 11. 


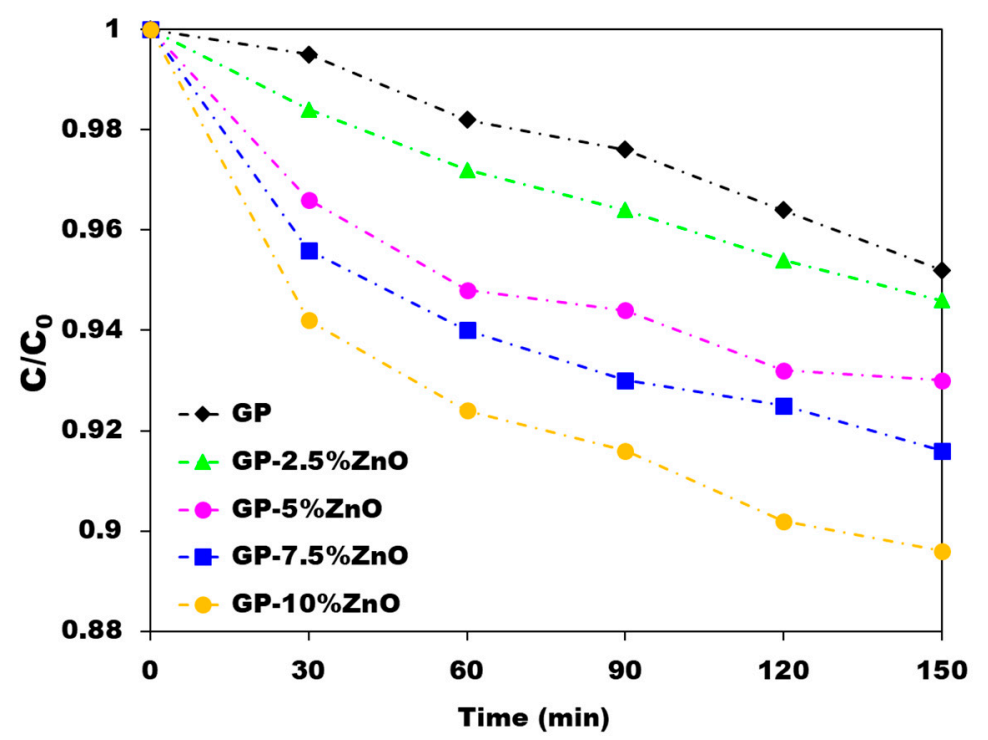

Figure 11. Degradation of methylene blue dye under UV irradiation by ZnO-based geopolymers containing different amounts of $\mathrm{ZnO}$ nanoparticles, based on the data of Zailan et al. [53].

A novel photocatalytic geopolymer based on ground granular blast furnace slag (GGBFS) containing $\mathrm{ZnO}$ and graphene has been developed by Zhang et al. [54] for applications such as solar hydrogen production and treatment of wastewater polluted with dye. The photoactive geopolymer was prepared by mixing the slag with $0.1 \mathrm{wt} . \%$ graphene, activating with $\mathrm{NaOH}$ solution and curing at $20^{\circ} \mathrm{C}$ under $90 \%$ relative humidity for $24 \mathrm{~h}$. This material was then ground and the charge-compensating $\mathrm{Na}^{+}$ions of the geopolymer exchanged with $\mathrm{NH}_{4}{ }^{+}$by treatment with $\mathrm{NH}_{4} \mathrm{NO}_{3}$ solution, followed by the introduction of zinc from a solution of $\left(\mathrm{CH}_{3} \mathrm{COO}\right)_{2} \mathrm{Zn}$. At low loadings, the $\mathrm{ZnO}$ was amorphous, but at higher $\mathrm{Zn}$ contents it was in the crystalline form of zincite. The photoactive geopolymer was dried at $65^{\circ} \mathrm{C}$ and calcined at $400{ }^{\circ} \mathrm{C}$ for $4 \mathrm{~h}$ in a nitrogen atmosphere. The resulting combination of the $\mathrm{ZnO}$, graphene and slag in a geopolymer of composition $14.45 \% \mathrm{ZnO} / \mathrm{GGBFS}$, designated $15 \mathrm{ZnO} / \mathrm{GGBFS}$, showed $92.7 \%$ degradation efficiency of basic violet $5 \mathrm{BN}$ dye in wastewater under UV irradiation (cf. degradation by the geopolymer matrix alone and $\mathrm{ZnO}$ alone, 9.7\% and 58.2\% respectively, under the same conditions). The degradation efficiency of this geopolymer composite was also relatively unchanged over five reaction cycles (Table 4) and also showed excellent photocatalytic activity for the production of hydrogen $(2281.3 \mu \mathrm{mol} / \mathrm{g})$ from water (Figure 12), compared with $\mathrm{ZnO}$ alone [54]. It was suggested that the slag-based geopolymer matrix acts as a support for the graphene and the photoactive $\mathrm{ZnO}$ semiconductor, which under irradiation produces photoinduced electrons in the conduction band. The proximity of the $\mathrm{ZnO}$ to the graphene enables the efficient transmission of these photoelectrons to the $\pi$-bond conjugate system of graphene, resulting in the efficient separation of photoinduced electron-hole pairs, producing the hydroxyl radicals responsible for the second-order kinetic photodegradation of dye-polluted waste waters [54].

Table 4. Degradation efficiency of basic violet 5BN dye by a slag-based geopolymer containing $0.1 \mathrm{wt} . \%$ graphene and $15 \mathrm{ZnO}$ under UV irradiation over five reaction cycles [54].

\begin{tabular}{cc}
\hline Cycle Number & Degradation (\%) \\
\hline 1 & 92.7 \\
2 & 90.6 \\
3 & 89.7 \\
4 & 88.5 \\
5 & 87.8 \\
\hline
\end{tabular}




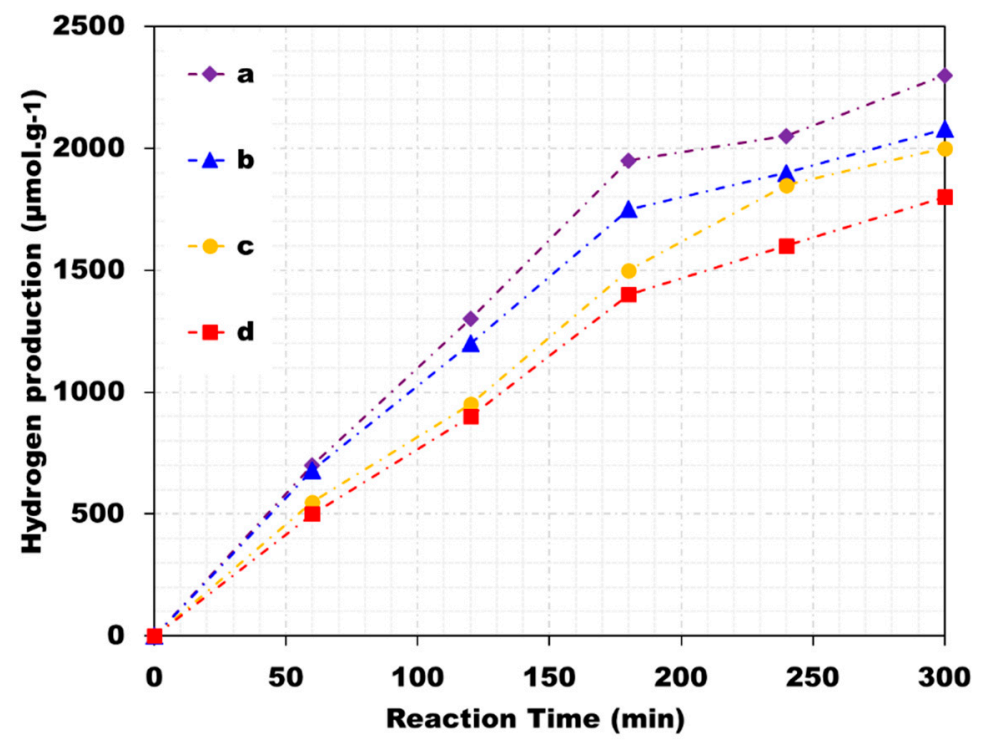

Figure 12. UV photocatalytic hydrogen production from water by $\mathrm{ZnO} /$ graphene GGBFS-based photocatalysts containing $0.01 \mathrm{wt} \%$ graphene, as a function of $\mathrm{ZnO}$ content. (a) $15 \mathrm{ZnO}$, (b) 10ZnO, (c) $20 \mathrm{ZnO},(\mathrm{d}) 2 \mathrm{ZnO}$. Based on the data of Zhang et al. [54].

Zhang et al. [55] have also reported the successful use of a GGBFS-based geopolymer containing graphene and $\mathrm{CdO}$ for the photodegradation of direct fast bordeaux dye in wastewater. The preparation of the photoactive geopolymer was similar to that described above for the $\mathrm{ZnO}$-graphene/GGBFs geopolymer composite, substituting a solution of $\mathrm{Cd}\left(\mathrm{NO}_{3}\right)_{2} \cdot 4 \mathrm{H}_{2} \mathrm{O}$ for $\mathrm{Zn}\left(\mathrm{CH}_{3} \mathrm{COO}\right)_{2}$ solution. Samples containing 1-16 wt.\% CdO were subjected to UV irradiation after equilibrating with the dye solution in the dark for $30 \mathrm{~min}$, but no measurements were reported to confirm that complete adsorption had occurred prior to irradiation. The most efficient degradation of the dye under UV irradiation (close to $100 \%$ after $100 \mathrm{~min}$ ) was obtained with the photocatalyst containing $8 \mathrm{wt} . \% \mathrm{CdO}$ (Figure 13). In contrast with the results for the corresponding $\mathrm{ZnO}$ photocomposite [55], the dye photodegradation by the $\mathrm{CdO}$ photocomposite followed first order kinetics [55].

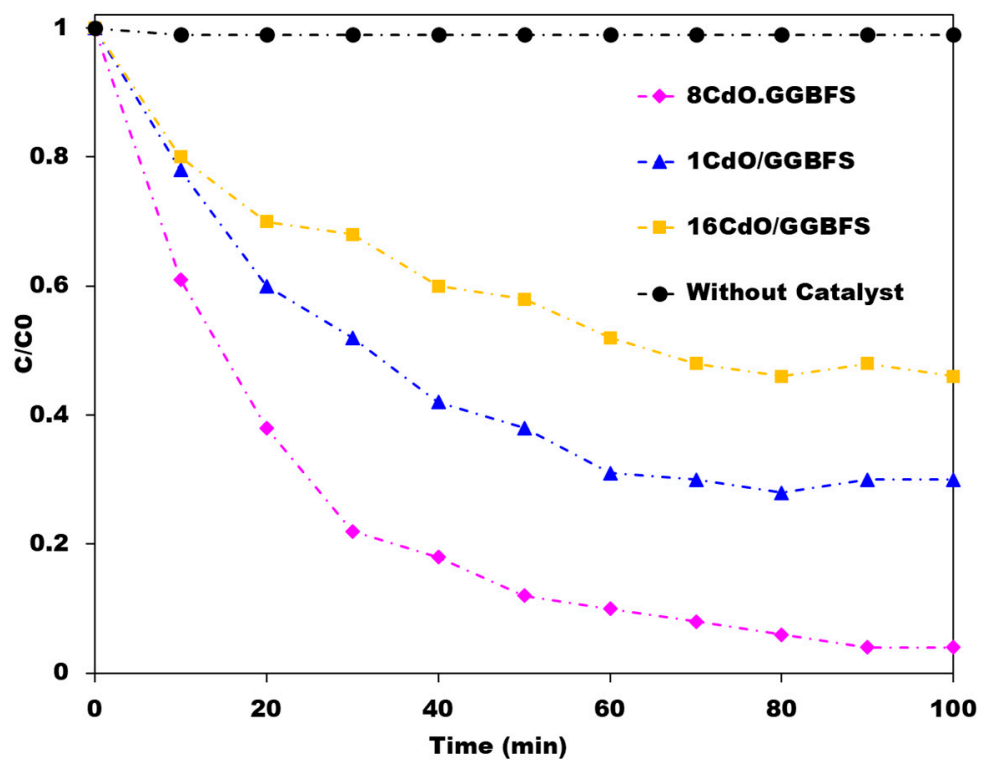

Figure 13. Residual concentration $\left(C / C_{0}\right)$ of direct fast Bordeaux dye under UV irradiation of by $\mathrm{CdO} /$ graphene GGBFS-based geopolymer photocatalysts as a function of $\mathrm{CdO}$ content, based on the data of Zhang et al. [55]. 
Saufi et al. [56] have reported an interesting geopolymer with intrinsic photoactive properties prepared from the mineral perlite, an aluminosilicate mineral containing $74.8 \mathrm{wt} . \% \mathrm{SiO}_{2}, 12.5 \mathrm{wt} . \%$ $\mathrm{Al}_{2} \mathrm{O}_{3}, 4.5$ wt. $\% \mathrm{Na}_{2} \mathrm{O}, 5.42$ wt. $\% \mathrm{~K}_{2} \mathrm{O}, 0.9$ wt. $\% \mathrm{Fe}_{2} \mathrm{O}_{3}$ and 0.7 wt. $\% \mathrm{CaO}$. After activation with $\mathrm{NaOH}$ and sodium silicate, the geopolymer was cured at $60^{\circ} \mathrm{C}$ for $24 \mathrm{~h}$. Although some of the experimental details of the photocatalytic investigation of this geopolymer are unclear, one of the experiments in which the material was not exposed to UV irradiation (i.e., possibly kept in the dark) decolourized a methylene blue dye solution by almost $89 \%$, presumably due to adsorption alone. Under UV irradiation, $97.9 \%$ decolourization was reported, but it is unclear from the discussion whether this represents a combination of adsorption and photocatalytic dye removal. The photocatalytic function of this geopolymer composite was suggested to be associated with the $\mathrm{Fe}_{2} \mathrm{O}_{3}$ component of the perlite, which almost completely removed methylene blue dye under UV irradiation in $4 \mathrm{~h}$ in a second-order kinetic process (Figure 14) [56]. These results open up the prospect of new types of geopolymers in which the photoactive moiety is supplied by one of the components naturally occurring in the aluminosilicate precursor.

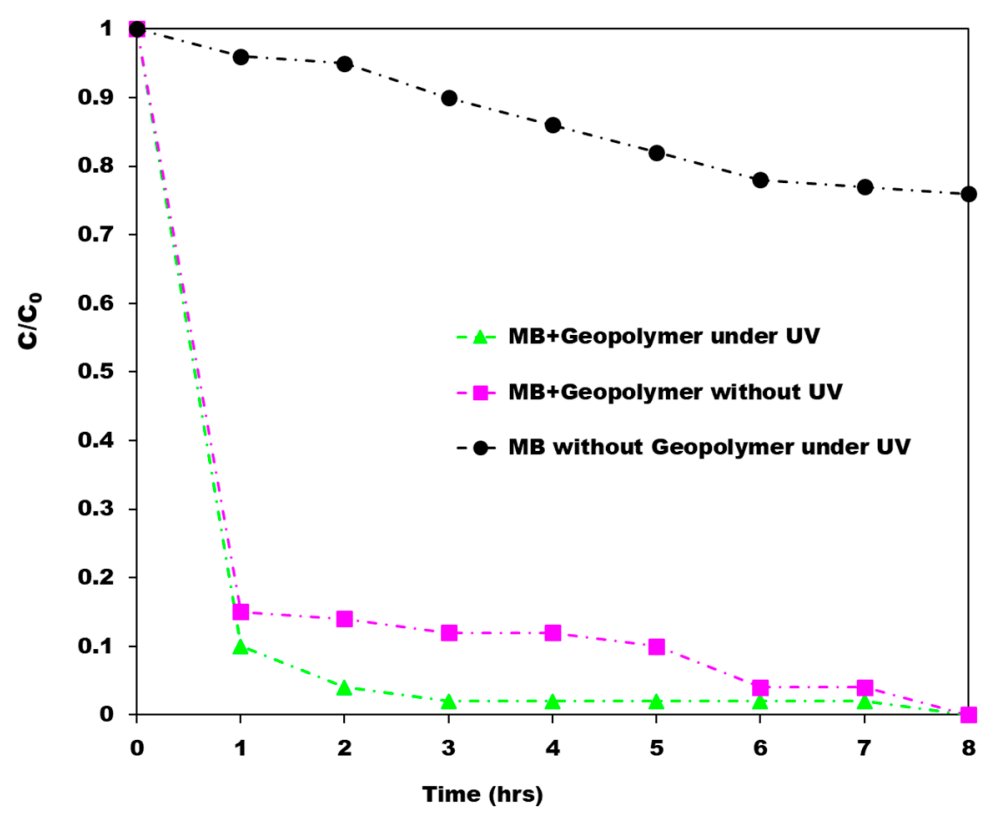

Figure 14. Change in the residual concentration $\left(C / C_{0}\right)$ of methylene blue dye upon exposure to a perlite-based geopolymer in the dark and under UV radiation, based on the data of Saufi et al. [56].

A fly ash-based geopolymer with similar intrinsic photoactivity was reported by Zhang et al. [57], in which the photoactive components were the $4.4 \% \mathrm{Fe}_{3} \mathrm{O}_{3}$ and $1.1 \% \mathrm{TiO}_{2}$ in the starting material. This geopolymer was shown to remove methylene blue dye from solution under UV irradiation with $92.8 \%$ efficiency through a combination of adsorption in the geopolymer pores following pseudo-second order kinetics, and photodegradation, following third-order kinetics [57]. The experiment was carried out by assuming the dye adsorption step had come to equilibrium after $30 \mathrm{~min}$ in the dark, after which the sample was subjected to UV irradiation and the fading of the dye was colourimetrically monitored as a function of time.

A control experiment in which the dye was exposed to UV irradiation in the absence of the photocatalyst indicated that under these conditions about $22.3 \%$ decolourization occurred, but adsorption accounted for a significantly greater effect (89.1\%). The greatest degree of dye removal $(92.8 \%)$ was found for the sample that had been equilibrated in the dark prior to UV exposure (Figure 15). 


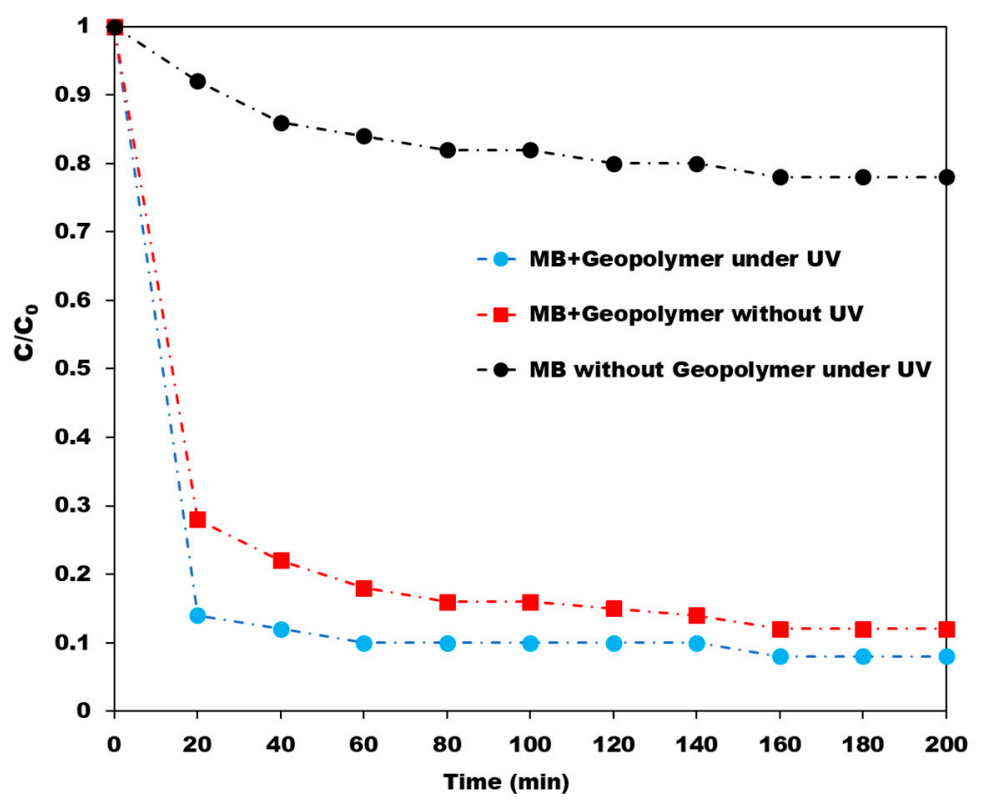

Figure 15. Change in the residual concentration $\left(C / C_{0}\right)$ of methylene blue dye upon exposure to a fly ash-based geopolymer in the dark and under UV radiation, based on the data of Zhang et al. [57].

He et al. [58] reported an unusual photoactive electroconductive geopolymer prepared by alkali activation of silicomanganese slag waste. The slag was blended with carbon black, activated with $\mathrm{NaOH}$, cured for $6 \mathrm{~h}$ at $80{ }^{\circ} \mathrm{C}$ and then powdered. The powder was converted to the $\mathrm{NH}_{4}{ }^{+}$form by immersion in a solution of $\mathrm{CH}_{3} \mathrm{COONH}_{4}$; washed and dried; and then impregnated with a solution of $\left(\mathrm{NH}_{4}\right)_{6} \mathrm{Mo}_{7} \mathrm{O}_{24} \cdot 4 \mathrm{H}_{2} \mathrm{O}$ before calcining at $400{ }^{\circ} \mathrm{C}$ for $4 \mathrm{~h}$ to produce a geopolymer containing $\mathrm{CaMoO}_{4}$ and carbon black [58]. In addition to its electroconductive properties, the photocatalyst containing an optimum $\mathrm{CaMoO}_{4}$ content of composition of photocatalyst was found to degrade BV5 dye, achieving close to $100 \%$ degradation under UV irradiation after $80 \mathrm{~min}$.

\section{Conclusions}

Geopolymers have been shown to be capable of forming photocatalytic nanocomposites for removal of hazardous pollutants from waste water or the atmosphere. These ecologically-friendly inorganic materials can be produced at temperatures below $100{ }^{\circ} \mathrm{C}$ from industrial wastes such as fly ash, blast furnace slags or mining residues, and their chemical and physical properties enable them to act as supports for photoactive species, including $\mathrm{TiO}_{2}, \mathrm{Cu}_{2} \mathrm{O}$ and $\mathrm{Fe}_{2} \mathrm{O}_{3}$, or carbon nanotubes and graphene. The combination of some of these species has been exploited in some cases to hinder electron-hole recombination, enhancing the performances of the photocatalysts. Geopolymers formed from industrial wastes such as fly ash or ground granulated blast furnace slag, or minerals such as perlite which contain photoactive $\mathrm{Fe}_{2} \mathrm{O}_{3}$ contaminants, also display intrinsic photoactivity without the need for additional components; these materials have been less widely reported, but would be worth further investigation. Apart from their ease of production, geopolymers and their photocatalytic composites, being inorganic materials, are capable of safe disposal when exhausted. Although the possibility of regenerating these composites has not specifically been addressed and would require further investigation, one study [54] has found them to be capable of several reaction cycles without significant reduction of photoactivity. In most cases the photocatalytic efficiencies of these compounds were determined by their degradation of a dye, such as methylene blue, both in the dark and under UV (solar) radiation. These studies indicated a dual mechanism of adsorption by the geopolymer matrix and photodegradation by the photoactive species present. Thus, photoactive geopolymers represent promising ecologically-friendly, cost-effective and efficient materials for the remediation of toxic environmental pollutants, but future work is required to more clearly distinguish between the 
adsorption and photodegradation processes and extent these applications beyond the removal of dyes from wastewater to the remediation of a wider range of hazardous environmental pollutants.

Funding: This research received no external funding.

Conflicts of Interest: The authors declare no conflict of interest.

\section{References}

1. Davidovits, J. Geopolymers. J. Therm. Anal. Calorim. 1991, 37, 1633-1656. [CrossRef]

2. Barbosa, V.F.; MacKenzie, K.J.; Thaumaturgo, C. Synthesis and characterisation of materials based on inorganic polymers of alumina and silica: Sodium polysialate polymers. Int. J. Inorg. Mater. 2000, 2, 309-317. [CrossRef]

3. MacKenzie, K.J.D.; Komphanchai, S.; Vagana, R. Formation of inorganic polymers (geopolymers) from 2:1 layer lattice aluminosilicates. J. Eur. Ceram. Soc. 2008, 28, 177-181. [CrossRef]

4. Lemougna, P.N.; MacKenzie, K.J.D.; Melo, U.C. Synthesis and thermal properties of inorganic polymers (geopolymers) for structural and refractory applications from volcanic ash. Ceram. Int. 2011, 37, 3011-3018. [CrossRef]

5. Xu, G.; Shi, X. Characteristics and applications of fly ash as a sustainable construction material: A state-of-the-art review. Resour. Conserv. Recycl. 2018, 136, 95-109. [CrossRef]

6. Temuujin, J.; Minjigmaa, A.; Bayarzul, U.; Kim, D.S.; Lee, S.-H.; Lee, H.J.; Ruescher, C.H.; MacKenzie, K.J. Properties of geopolymer binders prepared from milled pond ash. Mater. Constr. 2017, 67, 134. [CrossRef]

7. Turner, L.K.; Collins, F. Carbon dioxide equivalent $\left(\mathrm{CO}_{2}-\mathrm{e}\right)$ emissions: A comparison between geopolymer and OPC cement concrete. Constr. Build. Mater. 2013, 43, 125-130. [CrossRef]

8. MacKenzie, K.J.D. Inorganic Polymers (Geopolymers). In Encyclopedia of Polymer Science and Technology; Wiley: Hoboken, NJ, USA, 2017; pp. 1-31. ISBN 9780471440260. [CrossRef]

9. Santhi, K.; Rani, C.; Karuppuchamy, S. Synthesis and characterization of a novel $\mathrm{SnO} / \mathrm{SnO}_{2}$ hybrid photocatalyst. J. Alloys Compd. 2016, 662, 102-107. [CrossRef]

10. Boonen, E.; Beeldens, A. Photocatalytic roads: From lab tests to real scale applications. Eur. Transp. Res. Rev. 2012, 5, 79-89. [CrossRef]

11. Falah, M. Synthesis of New Composites of Inorganic Polymers (Geopolymers) with Metal Oxide Nanoparticles and Their Photodegradation of Organic Pollutants. Ph.D. Thesis, Victoria University of Wellington, Wellington, New Zealand, 2015. Available online: http://researcharchive.vuw.ac.nz/handle/10063/4847 (accessed on 8 October 2020).

12. Shen, S.; Kronawitter, C.; Kiriakidis, G. An overview of photocatalytic materials. J. Materiomics 2017, 3, 1-2. [CrossRef]

13. Karthikeyan, C.; Arunachalam, P.; Ramachandran, K.; Al-Mayouf, A.M.; Karuppuchamy, S. Recent advances in semiconductor metal oxides with enhanced methods for solar photocatalytic applications. J. Alloys Compd. 2020, 828, 154281. [CrossRef]

14. Provis, J.L.; Van Deventer, J. Geopolymerisation kinetics. Reaction kinetic modelling. Chem. Eng. Sci. 2007, 62, 2318-2329. [CrossRef]

15. Rowles, M.R.; Hanna, J.V.; Pike, K.J.; Smith, M.E.; O'Connor, B.H. 29 Si, 27 Al, 1 H and 23 Na MAS NMR study of the bonding character in aluminosilicate inorganic polymers. Appl. Magn. Reson. 2007, 32, 663-689. [CrossRef]

16. MacKenzie, K.J.D.; Smith, M.E. Multinuclear Solid State NMR of Inorganic Materials, Pergamon Materials Series; Pergamon/Elsevier: Oxford, UK, 2002; Volume 6, p. 304.

17. O'Connor, S.J.; MacKenzie, K.J.D.; Smith, M.E.; Hanna, J.V. Ion exchange in the charge-balancing sites of aluminosilicate inorganic polymers. J. Mater. Chem. 2010, 20, 10234. [CrossRef]

18. Ajmal, A.; Majeed, I.; Malik, R.N.; Idriss, H.; Nadeem, M.A. Principles and mechanisms of photocatalytic dye degradation on TiO2based photocatalysts: A comparative overview. RSC Adv. 2014, 4, 37003-37026. [CrossRef]

19. Galindo, C.; Jacques, P.; Kalt, A. Photodegradation of the aminoazobenzene acid orange 52 by three advanced oxidation processes: $\mathrm{UV} / \mathrm{H}_{2} \mathrm{O}_{2}, \mathrm{UV} / \mathrm{TiO}_{2}$ and $\mathrm{VIS} / \mathrm{TiO}_{2}$. J. Photochem. Photobiol. A Chem. 2000, 130, 35-47. [CrossRef] 
20. Zhao, J.; Chen, C.; Ma, W. Photocatalytic degradation of organic pollutants under visible light irradiation. Top. Catal. 2005, 35, 269-278. [CrossRef]

21. Maragatha, J.; Jothivenkatachalam, K.; Karuppuchamy, S. Synthesis and characterization of visible light-responsive carbon doped $\mathrm{Ti}_{4} \mathrm{O}_{7}$ photocatalyst. J. Mater. Sci. Mater. Electron. 2016, 27, 9233-9239. [CrossRef]

22. Nagalakshmi, M.; Karthikeyan, C.; Anusuya, N.; Brundha, C.; Basu, M.J.; Karuppuchamy, S. Synthesis of $\mathrm{TiO}_{2}$ nanofiber for photocatalytic and antibacterial applications. J. Mater. Sci. Mater. Electron. 2017, 28, 15915-15920. [CrossRef]

23. Mills, A.; Davies, R.H.; Worsley, D. Water purification by semiconductor photocatalysis. Chem. Soc. Rev. 1993, 22, 417. [CrossRef]

24. Wilke, K.; Breuer, H. The influence of transition metal doping on the physical and photocatalytic properties of titania. J. Photochem. Photobiol. A Chem. 1999, 121, 49-53. [CrossRef]

25. Falah, M.; MacKenzie, K.J.D.; Hanna, J.V.; Page, S.J. Novel photoactive inorganic polymer composites of inorganic polymers with copper (I) oxide nanoparticles. J. Mater. Sci. 2015, 50, 7374-7383. [CrossRef]

26. Kabra, K.; Chaudhary, R.; Sawhney, R.L. Treatment of hazardous organic and inorganic compounds through aqueous-phase photocatalysis: A review. Ind. Eng. Chem. Res. 2004, 43, 7683-7696. [CrossRef]

27. Hanus, M.J.; Harris, A.T. Nanotechnology innovations for the construction industry. Prog. Mater. Sci. 2013, 58, 1056-1102. [CrossRef]

28. Pacheco-Torgal, F.; Jalali, S. Nanotechnology: Advantages and drawbacks in the field of construction and building materials. Constr. Build. Mater. 2011, 25, 582-590. [CrossRef]

29. Zheng, K.; Chen, L.; Gbozee, M. Thermal stability of geopolymers used as supporting materials for TiO2 film coating through sol-gel process: Feasibility and improvement. Constr. Build. Mater. 2016, 125, 1114-1126. [CrossRef]

30. Fan, W.; Lai, Q.; Zhang, Q.; Wang, Y. Nanocomposites of $\mathrm{TiO}_{2}$ and reduced graphene oxide as efficient photocatalysts for hydrogen evolution. J. Phys. Chem. C 2011, 115, 10694-10701. [CrossRef]

31. Chen, L.; Zheng, K.; Liu, Y. Geopolymer-supported photocatalytic $\mathrm{TiO}_{2}$ film: Preparation and characterization. Constr. Build. Mater. 2017, 151, 63-70. [CrossRef]

32. Strini, A.; Roviello, G.; Ricciotti, L.; Ferone, C.; Messina, F.; Schiavi, L.; Corsaro, D.; Cioffi, R. $\mathrm{TiO}_{2}$-based photocatalytic geopolymers for nitric oxide degradation. Materials 2016, 9, 513. [CrossRef]

33. Bravo, P.I.; Malenab, R.A.; Shimizu, E.; Yu, D.E.; Promentilla, M.A. Synthesis of geopolymer spheres with photocatalytic activity. MATEC Web Conf. 2019, 268, 04007. [CrossRef]

34. Samuneva, B.; Kozhukharov, V.; Trapalis, C.; Kranold, R. Sol-gel processing of titanium- containing thin coatings-Part I. Preparation and structure. J. Mater. Sci. 1993, 28, 2353-2360. [CrossRef]

35. Gasca-Tirado, J.; Manzano-Ramírez, A.; Villaseñor-Mora, C.; Muñiz-Villarreal, M.; Zaldivar-Cadena, A.; Rubio-Avalos, J.; Borrás, V.A.; Mendoza, R.N. Incorporation of photoactive $\mathrm{TiO}_{2}$ in an aluminosilicate inorganic polymer by ion exchange. Microporous Mesoporous Mater. 2012, 153, 282-287. [CrossRef]

36. Yang, X.; Liu, Y.; Yan, C.; Peng, R.; Wang, H. Geopolymer-TiO 2 nanocomposites for photocsatalysis: Synthesis by one-step adding treatment versus two-step acidification calcination. Minerals 2019, 9, 658. [CrossRef]

37. Lertcumfu, N.; Jaita, P.; Thammarong, S.; Lamkhao, S.; Tandorn, S.; Randorn, C.; Tunkasiri, T.; Rujijanagul, G. Influence of graphene oxide additive on physical, microstructure, adsorption, and photocatalytic properties of calcined kaolinite-based geopolymer ceramic composites. Colloids Surf. A: Physicochem. Eng. Asp. 2020, 602, 125080. [CrossRef]

38. Gupta, K.; Khatri, O.P. Reduced graphene oxide as an effective adsorbent for removal of malachite green dye: Plausible adsorption pathways. J. Colloid Interface Sci. 2017, 501, 11-21. [CrossRef] [PubMed]

39. Gao, Y.; Wu, J.-C.; Chen, C.; Tan, X.; Hayat, T.; Alsaedi, A.; Cheng, C.; Chen, C. Impact of graphene oxide on the antibacterial activity of antibiotics against bacteria. Environ. Sci. Nano 2017, 4, 1016-1024. [CrossRef]

40. Gopalakrishnan, A.; Krishnan, R.; Thangavel, S.; Venugopal, G.; Kim, S.-J.; Arthi, G.; Rajasekar, K.; Sakthivel, T.; Gunasekaran, V. Removal of heavy metal ions from pharma-effluents using graphene-oxide nanosorbents and study of their adsorption kinetics. J. Ind. Eng. Chem. 2015, 30, 14-19. [CrossRef]

41. Shamsaei, E.; De Souza, F.B.; Yao, X.; Benhelal, E.; Akbari, A.; Zhuang, J. Graphene-based nanosheets for stronger and more durable concrete: A review. Constr. Build. Mater. 2018, 183, 642-660. [CrossRef]

42. Zhang, Y.J.; Yang, M.Y.; Zhang, L.; Zhang, K.; Kang, L. A new graphene/geopolymer nanocomposite for degradation of dye wastewater. Integr. Ferroelectr. 2016, 171, 38-45. [CrossRef] 
43. Zhang, Y.J.; He, P.Y.; Zhang, Y.X.; Chen, H. A novel electroconductive graphene/fly ash-based geopolymer composite and its photocatalytic performance. Chem. Eng. J. 2018, 334, 2459-2466. [CrossRef]

44. Huang, L.; Peng, F.; Yu, H.; Wang, H. Preparation of cuprous oxides with different sizes and their behaviors of adsorption, visible-light driven photocatalysis and photocorrosion. Solid State Sci. 2009, 11, 129-138. [CrossRef]

45. Zheng, Z.; Huang, B.; Wang, Z.; Guo, M.; Qin, X.; Zhang, X.; Wang, P.; Dai, Y. Crystal Faces of Cu $\mathrm{Cu}_{2} \mathrm{O}$ and Their stabilities in photocatalytic reactions. J. Phys. Chem. C 2009, 113, 14448-14453. [CrossRef]

46. Saleh, T.A. Syntheses and Applications of Carbon Nanotubes and Their Composites; InTech Open: London, UK, 2013. [CrossRef]

47. Kumar, M. Effect of Nanomaterials on the Properties of Geopolymer Mortars and Concrete; Elsevier BV: Amsterdam, The Netherlands, 2018; Volume 5, pp. 9035-9040.

48. Mahmoodi, N.M. Synthesis of magnetic carbon nanotube and photocatalytic dye degradation ability. Environ. Monit. Assess. 2014, 186, 5595-5604. [CrossRef]

49. Bi, S.; Liu, M.; Shen, J.; Hu, X.; Zhang, L. Ultrahigh self-sensing performance of geopolymer nanocomposites via unique interface engineering. ACS Appl. Mater. Interfaces 2017, 9, 12851-12858. [CrossRef]

50. Huang, L.; Peng, F.; Wang, H.; Yu, H.; Li, Z. Preparation and characterization of $\mathrm{Cu}_{2} \mathrm{O} / \mathrm{TiO}_{2}$ nano-nano heterostructure photocatalysts. Catal. Commun. 2009, 10, 1839-1843. [CrossRef]

51. Falah, M.; MacKenzie, K.J.D. Synthesis and properties of novel photoactive composites of P25 titanium dioxide and copper (I) oxide with inorganic polymers. Ceram. Int. 2015, 41, 13702-13708. [CrossRef]

52. Falah, M.; MacKenzie, K.J.D.; Knibbe, R.; Page, S.J.; Hanna, J.V. New composites of nanoparticle Cu (I) oxide and titania in a novel inorganic polymer (geopolymer) matrix for destruction of dyes and hazardous organic pollutants. J. Hazard. Mater. 2016, 318, 772-782. [CrossRef]

53. Zailan, S.N.; Bouaissi, A.; Mahmed, N.; Abdullah, M.M.A.B. Influence of ZnO Nanoparticles on Mechanical Properties and Photocatalytic Activity of Self-cleaning ZnO-Based Geopolymer Paste. J. Inorg. Organomet. Polym. Mater. 2019, 30, 2007-2016. [CrossRef]

54. Zhang, Y.J.; He, P.Y.; Yang, M.Y.; Chen, H.; Liu, L.C. Renewable conversion of slag to graphene geopolymer for $\mathrm{H} 2$ production and wastewater treatment. Catal. Today 2019. [CrossRef]

55. Zhang, Y.J.; He, P.Y.; Chen, H. A novel CdO/graphene alkali-activated steel slag nanocomposite for photocatalytic degradation of dye wastewater. Ferroelectrics 2018, 522, 1-8. [CrossRef]

56. Saufi, H.; El Alouani, M.; Alehyen, S.; El Achouri, M.; Aride, J.; Taibi, M. Photocatalytic degradation of methylene blue from aqueous medium onto perlite-based geopolymer. Int. J. Chem. Eng. 2020, 2020, 1-7. [CrossRef]

57. Zhang, Y.; Liu, L. Fly ash-based geopolymer as a novel photocatalyst for degradation of dye from wastewater. Particuology 2013, 11, 353-358. [CrossRef]

58. He, P.Y.; Zhang, Y.J.; Chen, H.; Liu, L.C. Development of an eco-efficient $\mathrm{CaMoO}_{4} / \mathrm{electroconductive}^{-}$ geopolymer composite for recycling silicomanganese slag and degradation of dye wastewater. J. Clean. Prod. 2019, 208, 1476-1487. [CrossRef]

(C) 2020 by the authors. Licensee MDPI, Basel, Switzerland. This article is an open access article distributed under the terms and conditions of the Creative Commons Attribution (CC BY) license (http://creativecommons.org/licenses/by/4.0/). 